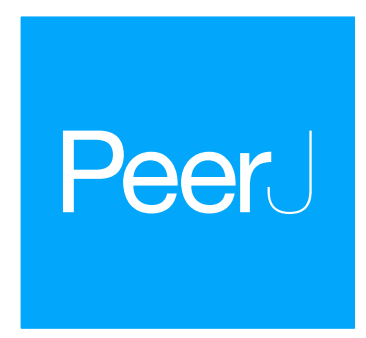

\title{
Disentangling the mechanisms of mate choice in a captive koala population
}

\author{
Parice A. Brandies ${ }^{1}$, Catherine E. Grueber ${ }^{1,2}$, Jamie A. Ivy ${ }^{2}$, \\ Carolyn J. Hogg ${ }^{1}$ and Katherine Belov ${ }^{1}$ \\ ${ }^{1}$ School of Life and Environmental Sciences, University of Sydney, Sydney, NSW, Australia \\ ${ }^{2}$ San Diego Zoo Global, San Diego, CA, USA
}

\section{ABSTRACT}

Successful captive breeding programs are crucial to the long-term survival of many threatened species. However, pair incompatibility (breeding failure) limits sustainability of many captive populations. Understanding whether the drivers of this incompatibility are behavioral, genetic, or a combination of both, is crucial to improving breeding programs. We used 28 years of pairing data from the San Diego Zoo koala colony, plus genetic analyses using both major histocompatibility complex (MHC)-linked and non-MHC-linked microsatellite markers, to show that both genetic and non-genetic factors can influence mating success. Male age was reconfirmed to be a contributing factor to the likelihood of a koala pair copulating. This trend could also be related to a pair's age difference, which was highly correlated with male age in our dataset. Familiarity was reconfirmed to increase the probability of a successful copulation. Our data provided evidence that females select mates based on MHC and genome-wide similarity. Male heterozygosity at MHC class II loci was associated with both pre- and post-copulatory female choice. Genome-wide similarity, and similarity at the MHC class II DAB locus, were also associated with female choice at the post-copulatory level. Finally, certain MHC-linked alleles were associated with either increased or decreased mating success. We predict that utilizing a variety of behavioral and MHC-dependent mate choice mechanisms improves female fitness through increased reproductive success.

Submitted 22 December 2017

Accepted 23 July 2018

Published 21 August 2018

Corresponding author

Katherine Belov,

kathy.belov@sydney.edu.au

Academic editor

Haseeb Khan

Additional Information and

Declarations can be found on page 23

DOI 10.7717/peerj.5438

(c) Copyright

2018 Brandies et al.

Distributed under

Creative Commons CC-BY 4.0

OPEN ACCESS
This study highlights the complexity of mate choice mechanisms in a species, and the importance of ascertaining mate choice mechanisms to improve the success of captive breeding programs.

Subjects Animal Behavior, Conservation Biology

Keywords Mate choice, Captive breeding, Genetic compatibility, Major histocompatibility complex (MHC), Male heterozygosity, Microsatellites

\section{INTRODUCTION}

Captive breeding programs contribute to species conservation and are one of the conservation tools used to prevent extinction (Fa, Funk \& O'Connell, 2011). The number of endangered and critically endangered species has been growing every year, largely due to human activities (IUCN, 2016). Currently there are almost 25,000 threatened species on the IUCN red list and the need for effective captive breeding programs is greater than ever before (IUCN, 2016). However, approximately 50\% of captive populations are 
not sustainable: animals are not reliably breeding to replacement, nor retaining the required levels of genetic diversity (a goal typically set at $\geq 90 \%$ of wild source gene diversity) (Lees \& Wilcken, 2009).

Many captive breeding programs are managed using a mean kinship strategy that aims to pair individuals that are least related to each other (based on the pedigree) (Ballou et al., 2010). Although this strategy has been widely applied through the zoo industry for the past few decades (Ballou \& Lacy, 1995), low breeding rates may occur due to mate incompatibility between individuals in prescribed pairs (Asa, Traylor-Holzer \& Lacy, 2011a; Lindburg \& Fitch-Snyder, 1994; Martin-Wintle et al., 2015; Quader, 2005). New strategies that incorporate mate choice into conservation efforts are important for enhancing animal productivity and increasing the sustainability of captive populations (Asa, Traylor-Holzer \& Lacy, 2011a, 2011b; Lindburg \& Fitch-Snyder, 1994; Wedekind, 2002).

Mate choice occurs as a result of non-random allocation of reproductive investment by individuals (Edward, 2015; Paul, 2002). Its mechanisms can be pre-copulatory, whereby visual, chemical, acoustic or behavioral cues influence the likelihood of mating, and/or post-copulatory, whereby copulatory plugs, sperm destruction and other mechanisms alter insemination or fertilization success (reviewed in Neff \& Pitcher, 2005; Paul, 2002). Recent literature has demonstrated the importance of the genetic determinants of mate choice in a wide range of species (for an overview of recent publications on this topic, see Table 1). There are currently three main, non-mutually exclusive hypotheses that can explain why the choosier sex (often females) selects mates based on genetic characteristics: (A) quantity of alleles, (B) genetic compatibility between mates, and (C) advantage of particular alleles (reviewed in Kamiya et al., 2014; Setchell \& Huchard, 2010). Under the quantity of alleles hypothesis, females experience a fitness advantage by mating with males with greater heterozygosity, or those that carry the greatest number of alleles and hence have the highest genetic diversity (Agbali et al., 2010; Kamiya et al., 2014; Penn \& Potts, 1999). Under the genetic compatibility hypothesis, females that mate with males that are genetically dissimilar, or with haplotypes that will best complement the females', experience a fitness advantage through increased offspring survival or increased offspring genetic diversity (Neff \& Pitcher, 2005; Tregenza \& Wedell, 2000). Finally, the third hypothesis suggests females prefer males harboring particular alleles that provide offspring with greater immunity to parasites and/or infectious diseases, as often only one or a few alleles provide resistance to a specific pathogen (Bonneaud et al., 2005; Penn \& Potts, 1999).

These hypotheses may apply genome-wide, or to specific loci, such as genes of the major histocompatibility complex (MHC). It is well known that MHC genes play a vital role in the vertebrate adaptive immune response (Balakrishnan \& Adams, 1995). Within the MHC gene family there are two main classes of molecules: class I molecules bind virus-derived peptides, and class II molecules bind peptides from extracellular bacteria and larger parasites (Balakrishnan \& Adams, 1995; Milinski, 2006). Therefore, having many different MHC alleles increases the ability to respond to a larger range of pathogens (Penn \& Potts, 1999). We focused on classical class II MHC genes due to their purported role in mammalian mate choice (Table 1). 


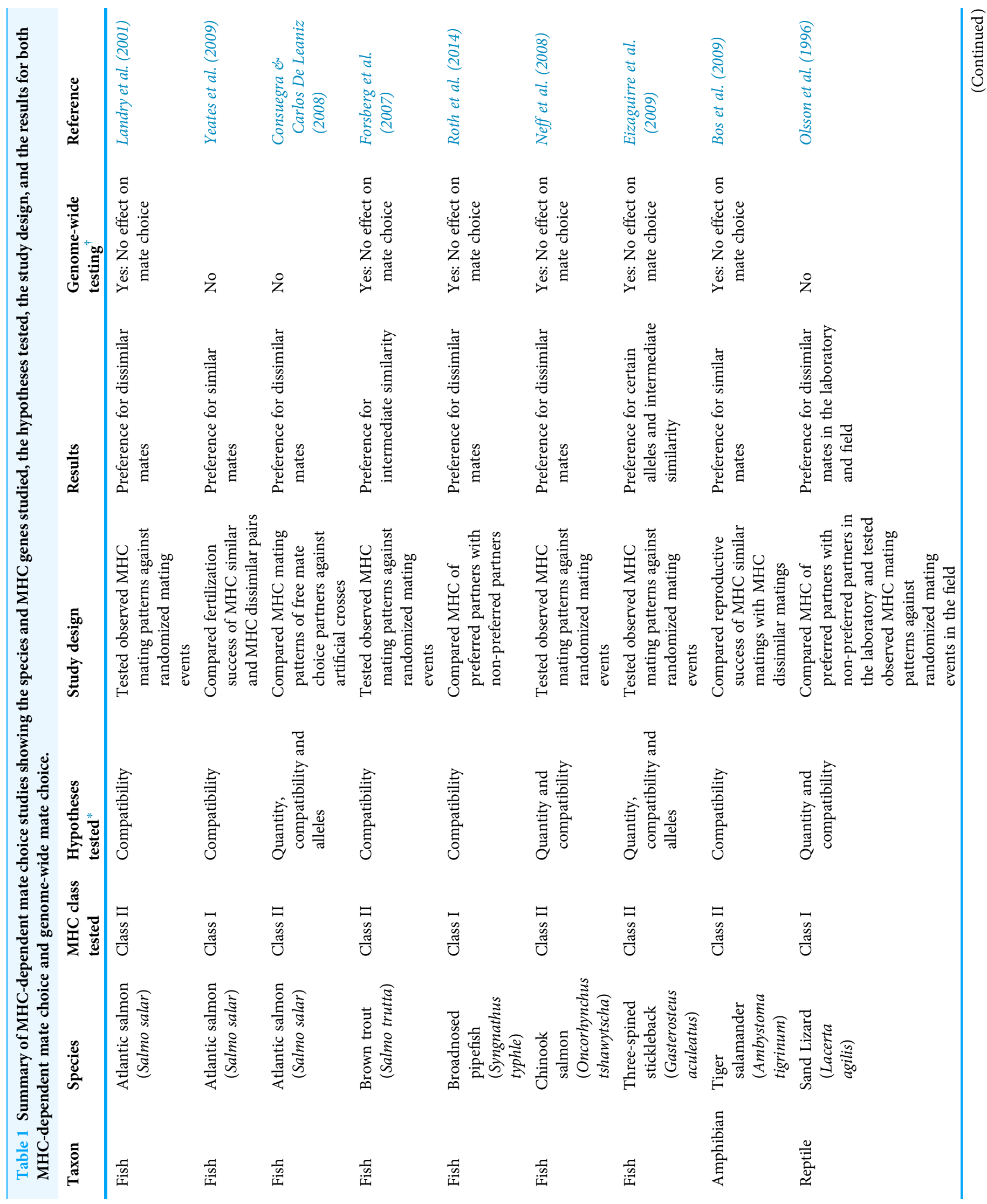




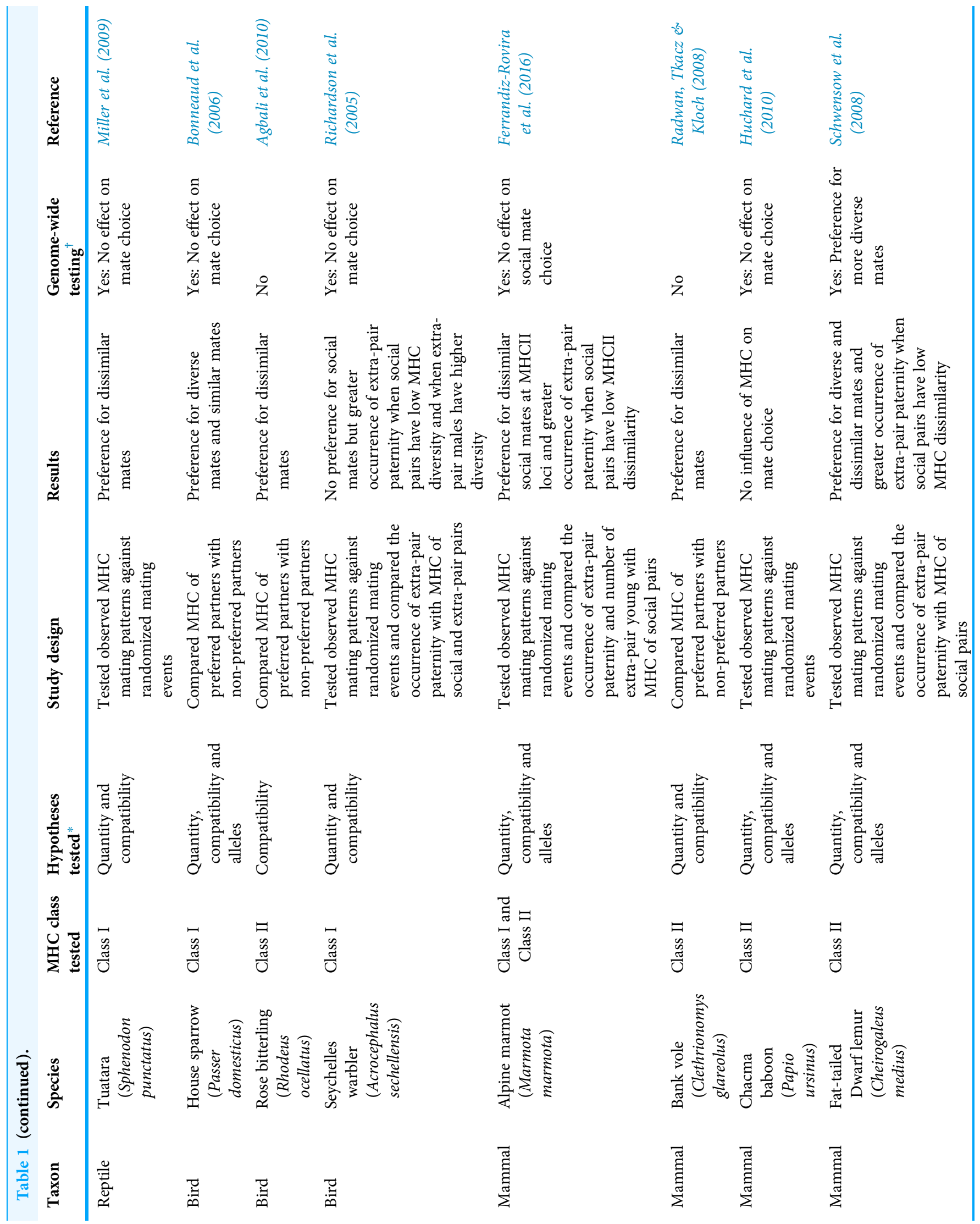




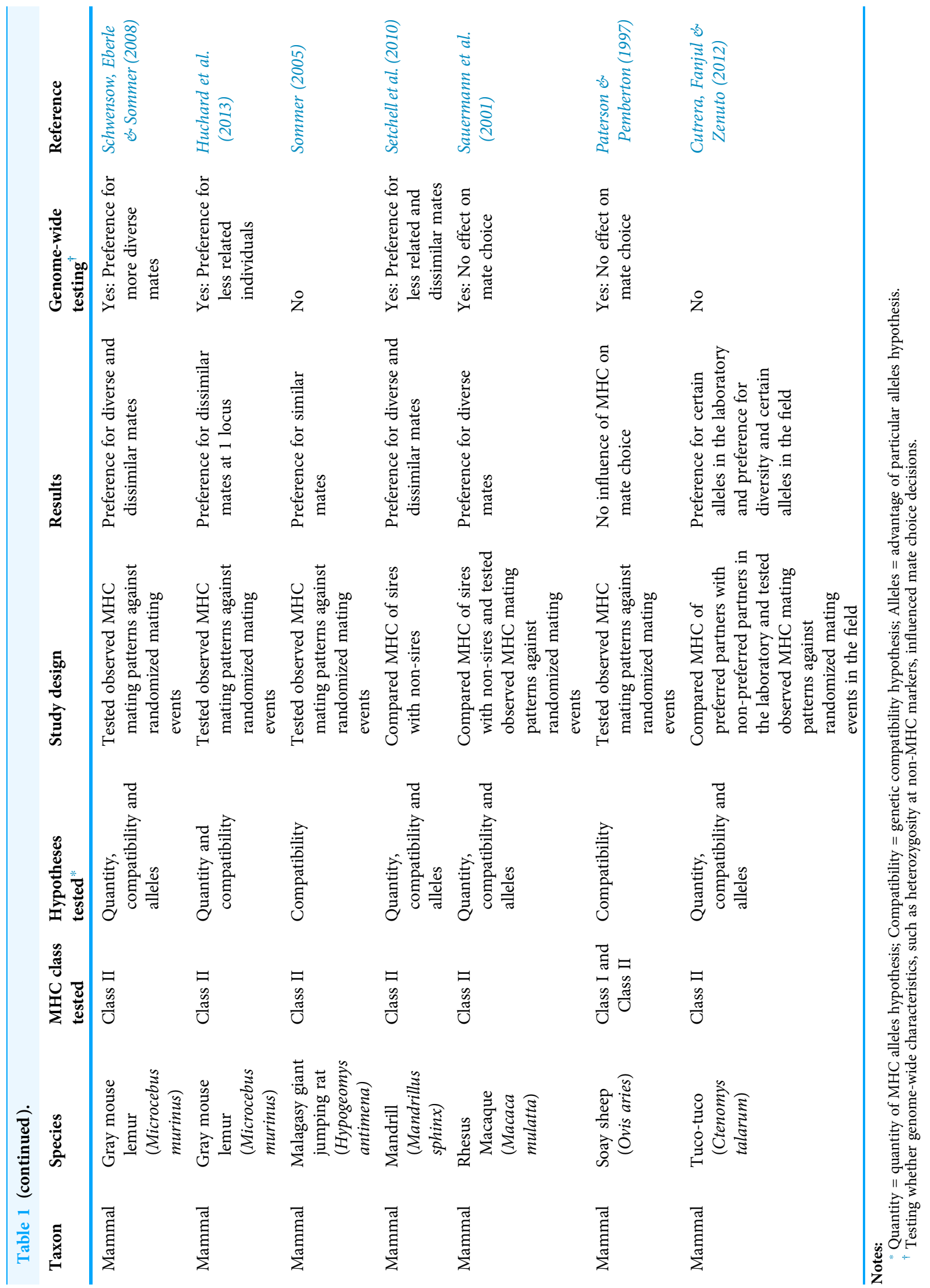




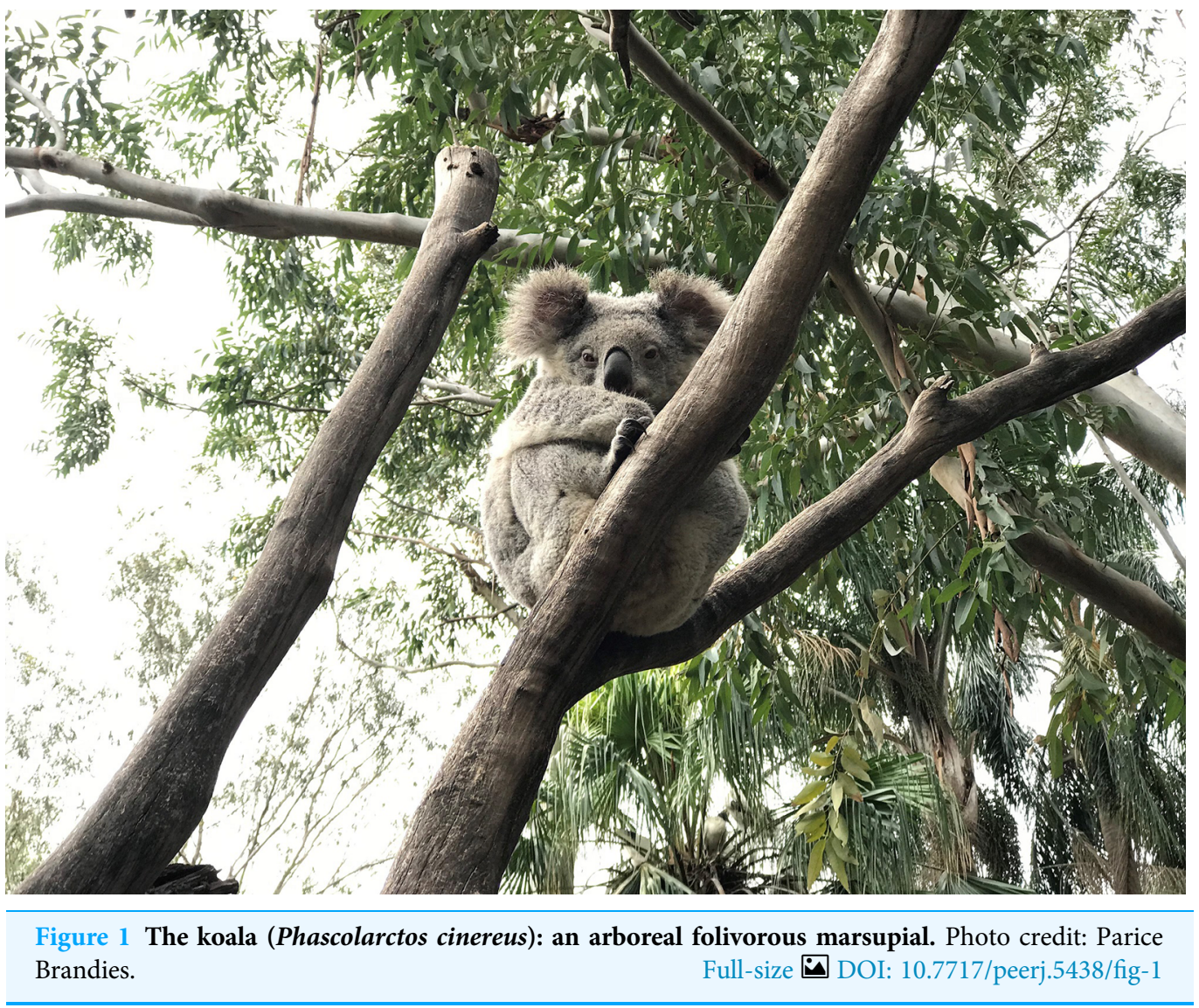

Numerous studies have found evidence for one or more of the proposed hypotheses, considering both genome-wide and MHC-dependent mate preferences (Table 1). Fish and reptiles often show a preference for mates that are more dissimilar at MHC loci, in accordance with the genetic compatibility hypothesis. Birds and mammals have been found to show preferences for both diverse and dissimilar mates (under the quantity of alleles and genetic compatibility hypotheses respectively) (Table 1). In other instances, fish and mammal species show preferences for specific MHC alleles in line with the advantage of particular alleles hypothesis (Eizaguirre et al., 2009; Cutrera, Fanjul \& Zenuto, 2012). Interestingly, many studies have examined the influence of genome-wide diversity on mate choice preferences. In mammalian species there is a preference for mates that are more diverse or dissimilar overall (Table 1). These studies have been crucial in demonstrating the importance of genetic determinants of mate choice; however, it is also important to consider other, non-genetic factors that may underlie mate choice decisions.

In this study, we investigated the role of mate choice in the San Diego Zoo koala colony (Fig. 1). San Diego Zoo's breeding program commenced in 1981, and houses the largest koala colony outside of Australia. As a managed zoo population, koalas are bred using a mean kinship strategy, restricting free access to mates. Despite increased pairing efforts (Fig. 2), the colony has shown significant declines in copulation and breeding success over time (Fig. 3). Familiarity and age have previously been proposed to be 


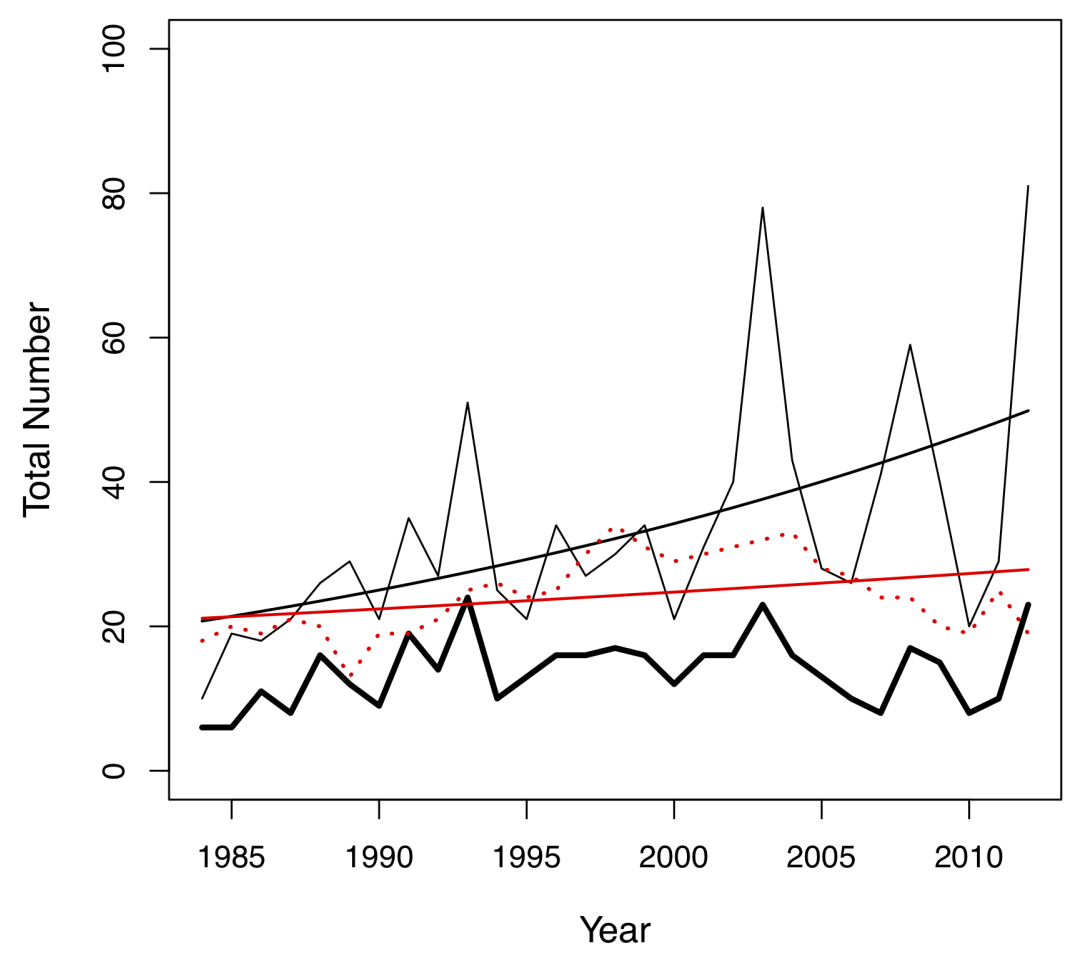

Figure 2 Changes in the total number of pairing events (thin black line), unique male-female pair combinations (thick black line) and individuals in the colony (red dotted line) per year in the San Diego Zoo koala population over time $(n=29$ years). Changes were modelled using generalized linear models (GLMs) with Poisson distribution. A trend line is plotted for the total number of pairing events $(\beta=0.03, \mathrm{SE}=0.004, p<0.001$, black line $)$ and total number of individuals in the colony $(ß=0.01$, $\mathrm{SE}=0.005, p=0.028$, red line). Full-size $\boldsymbol{0}$ DOI: 10.7717 /peerj.5438/fig-2

important factors involved in captive koala mate choice (Bercovitch et al., 2006), while evidence for size-mediated sexual selection in the koala is contradictory due to variable results (Bercovitch et al., 2006; William \& Bercovitch, 2011). The vomeronasal organ of the koala is predicted to play a role in MHC-based olfactory discrimination (Hegde, 2003) and suggests a potential mechanism for this species to select mates based on genetic characteristics in natural settings.

In other species, studies of MHC-dependent mate choice have employed MHC typing techniques to examine links between MHC genes and mate choice patterns (Huchard et al., 2010). However, due to the large numbers of duplicated MHC loci throughout marsupial genomes (Belov et al., 2013; Nei, Gu \& Sitnikova, 1997), obtaining genotypes for individual koalas at multiple MHC loci using current MHC typing methods is impractical. Furthermore, a recent meta-analysis revealed that a multi-locus approach is necessary for testing MHC-dependent mate choice associations (Kamiya et al., 2014). MHC-linked microsatellites have been shown to be good proxies for variation at MHC loci and are popular as an accurate, fast and cost-effective alternative to genotyping individuals at multiple MHC loci (Cheng \& Belov, 2012; Cheng et al., 2009a; Crouau-Roy et al., 1996). The recent characterization of MHC genes in the koala genome (Johnson et al., 2018) enables specific MHC-linked microsatellites to be identified in variable, single-copy 
A

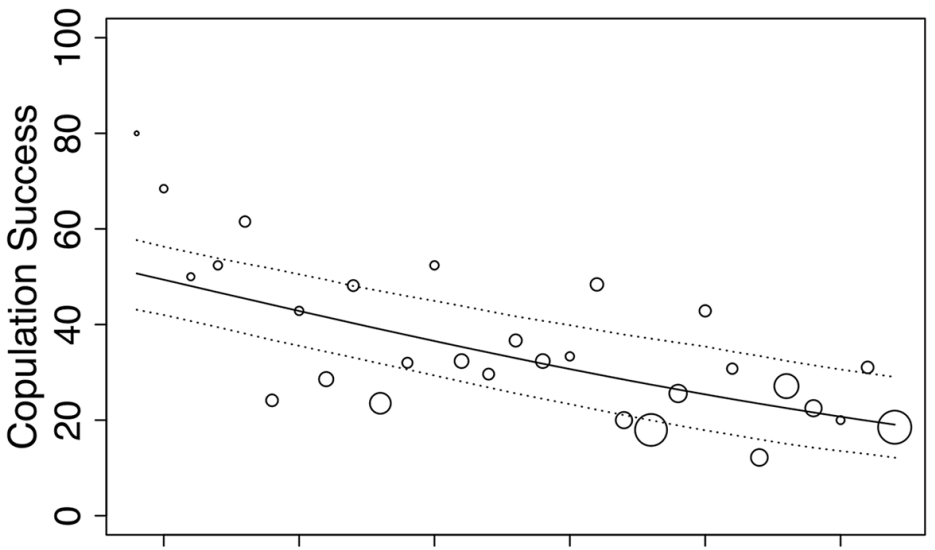

B

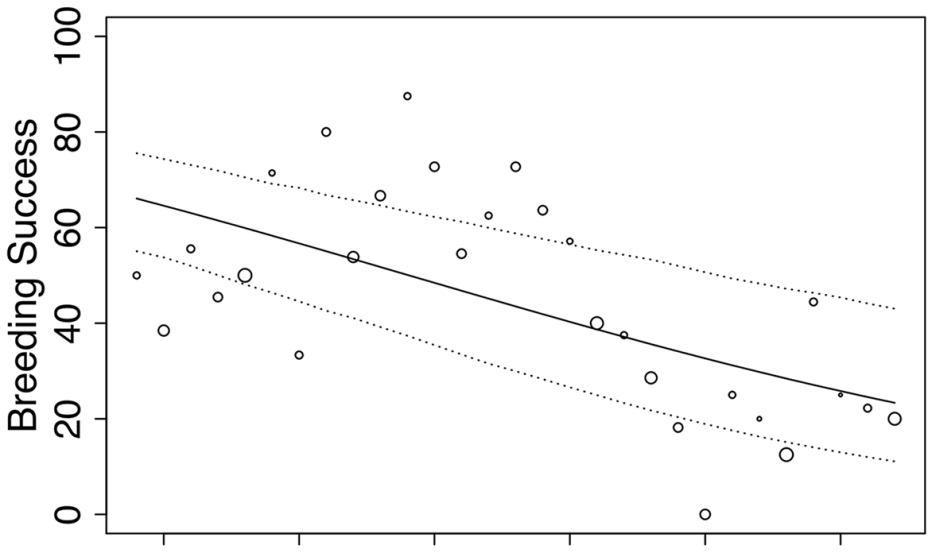

C

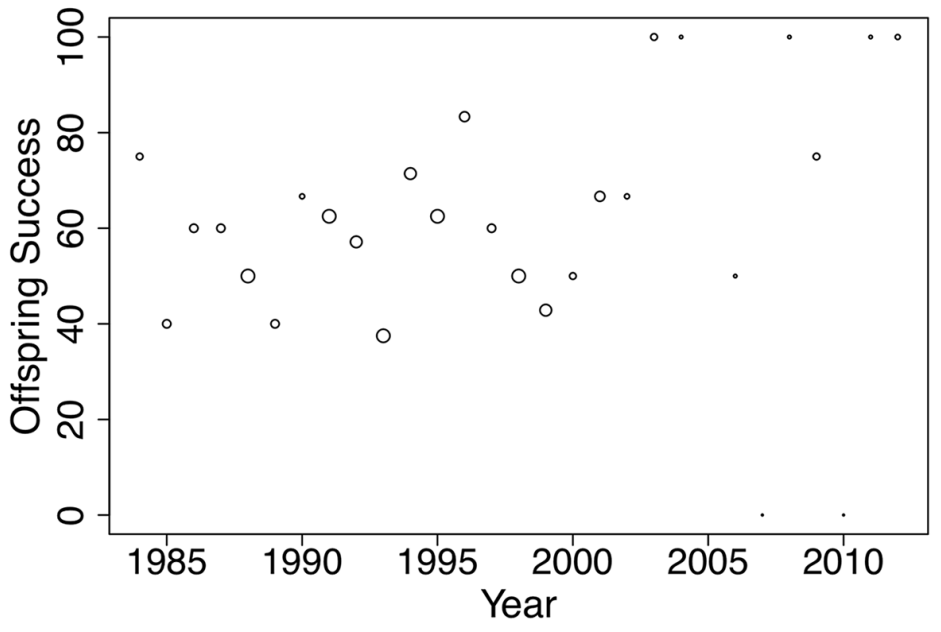

Figure 3 Changes in (A) copulation success, (B) breeding success and (C) offspring success rates of the San Diego Zoo koala population over time ( $n=29$ years). Changes were modelled using GLMs with binomial distribution. Trend lines are plotted for copulation success $(B=-0.05, \mathrm{SE}=0.009, p<0.001)$ and breeding success $(\beta=-0.07, \mathrm{SE}=0.015, p<0.001)$. Dotted lines represent $95 \% \mathrm{CI}$ obtained by parametric bootstrapping of the intercept and slope. Point size correlates to number of pairings, number of copulations and number of offspring in (A), (B) and (C), respectively.

Full-size $ض$ DOI: $10.7717 /$ peerj.5438/fig-3 
regions, overcoming the difficulties of previous MHC typing approaches. Here, we employ MHC-linked microsatellites to quantify diversity at MHC and non-MHC-linked microsatellites to quantify genome-wide diversity (Roth et al., 2014). Determining how species make mate choice decisions, and the extent to which both non-genetic and genetic factors influence breeding success in captive populations, will enable more effective captive breeding strategies and assist in improving the sustainability of captive breeding programs (Asa, Traylor-Holzer \& Lacy, 2011a; Quader, 2005).

Our study aims to (1) investigate non-genetic factors (such as age and familiarity) that may influence mate choice in captive koalas colony using detailed pairing records; and (2) test the three mate choice hypotheses (quantity of alleles, genetic compatibility and advantage of particular alleles) in regard to both MHC-dependent (using MHC-linked microsatellites) and genome-wide (using non-MHC-linked microsatellites) mating preferences.

\section{METHODS}

\section{Study samples}

A total of 70 koala DNA samples were extracted from banked whole blood and tissue samples (previously collected under San Diego Zoo Global IACUC protocols 10-008, 10-009, 11-029, 14-034) using either standard phenol-chloroform extraction, or the QIAamp DNA Mini Kit (Qiagen, Hilden, Germany) following manufacturer's directions. Detailed pairing records, and studbook data, were provided by the Association of Zoos and Aquariums North American Regional Studbook Keeper (Chris Hamlin, personal communication, April 2017). These pairing records spanned 1984-2012 and contained mate choice data and breeding outcomes for every pairing $(n=964)$ at the zoo throughout this period. Breeding recommendations are reviewed annually, and predominately follow a minimize kinship strategy (Ballou \& Lacy, 1995). During pairing, oestrous females are placed with males in enclosed cubicles for 5-10 min and mating behavior is monitored throughout this time (Bercovitch et al., 2006). If the pair does not copulate, the female and male may be paired with other conspecifics, or the same pairing may be trialed again at a later time. This pairing process means both female and male koalas are often exposed to multiple individuals of the opposite sex within and between seasons. We are therefore able to determine whether mate choice is occurring at the pre-copulatory level (i.e., copulation success as a proportion of pairing attempts) or post-copulatory level (i.e., breeding success (production of offspring) as a proportion of copulations), and whether it affects offspring success (offspring that survive more than 1 year as a proportion of offspring produced).

DNA samples were available for individuals across 28 years of pairing data (Fig. S1), accounting for $51 \%$ of the individuals and $49 \%$ of the pairings in the complete dataset (Table S1). A total of 22 sampled koalas were never paired for breeding and were excluded from the final mate choice analyses. These koalas were genotyped during the study and included in marker diversity statistics (see "Marker diversity" in the Supplemental Information) to maximize sample sizes where possible. All non-genetic factors were analyzed using the complete pairing dataset (including unsampled koalas). 


\section{Non-genetic determinants of koala mate choice}

We used generalized linear models (GLMs) in R v 3.4.0 (R Core Team, 2017) to test for non-genetic effects, including year, age and familiarity, on mating success (copulation, breeding and offspring success; see below). GLMs were performed with binomial distribution as follows: for each pairing event $(n=964)$ we modelled whether the pair successfully copulated (1) or did not copulate (0), with predictor variables including year of the pairing (to account for changes in the breeding program over time), age of the female, age of the male and the number of years the male and female had previously been paired together (as a measure of familiarity). Age $^{2}$ was also included, as the relationship between age and mating success was not predicted to be linear (Rose, 1991). The dataset was then subset into only those pairs that successfully copulated $(n=304)$ and the same predictor variables were modelled against whether each of these pairs successfully bred (produced offspring) (1) or did not breed (0). The dataset was then further subdivided into only those pairs that successfully bred $(n=134)$ and the same predictor variables were modelled against whether those pairs produced offspring that survived more than 1 year (1) or did not survive more than 1 year (0).

Male body mass is a strong predictor of male koala breeding success in the wild (William \& Bercovitch, 2011) and correlates strongly with male age (Tobey et al., 2006). We did not have male body mass available for our study animals. As age difference between the male and female was also highly correlated with both female and male age $(\rho=-0.58, p=<0.001$ and $\rho=0.76, p=<0.001$, respectively, Table S2) it was not included in the model. As a result, any effects of male age that we observe may also be reflecting the effect of male body mass and/or the age difference of the pair; female age effects may also be driven by age difference.

Although some pairs were repeated in multiple years, Pair ID was not included as a random factor due to the majority of pairs (60\%) only being represented in 1 year of the dataset (Fig. S2) (models with Pair ID fitted as a random intercept did not converge). Variance inflation factors (VIFs; Belsley, Kuh \& Welsch, 1980) were calculated for the remaining predictor variables to ensure there were no adverse effects of multicollinearity. All VIFs were $<2$ and so year, female age, male age and familiarity were included in the models (Belsley, Kuh \& Welsch, 1980). Model predictors were standardized by

subtracting the mean and dividing by two standard deviations (following Gelman, 2008) to facilitate inference of regression coefficients within and between models (Schielzeth, 2010). Model fitted values were back-transformed onto the natural scale for plotting and interpretation.

\section{MHC genotyping}

Major histocompatibility complex-linked primers were designed within $10 \mathrm{~kb}$ of MHC Class II genes that had been annotated by the Koala Genome Consortium (Johnson et al., 2018). RepeatMasker (Smit, Hubley \& Green, 2013-2015) was used to identify microsatellite sequences $<10 \mathrm{~kb}$ away from the MHC genes (Cheng et al., 2009b). Candidate microsatellite sequences (PhciDBB001M3, PhciDCBM1 and MHCIIDAB001M1) were selected based on minimal interruptions to the repeat sequence 
and low proximity to other repeat regions. These microsatellites were linked to genes of the DB, DC and DA families respectively (Abts, Ivy \& DeWoody, 2015; Lau et al., 2013, 2014a; Lau, Griffith \& Higgins, 2014b), allowing us to incorporate a representative for each classical marsupial MHC class II family (Belov et al., 2006; Belov, Lam \& Colgan, 2004). The repeat motifs for each microsatellite were $(\mathrm{TG})_{13},(\mathrm{GA})_{28}$ and $(\mathrm{AC})_{29}$ respectively. We extracted these microsatellite sequences with $300 \mathrm{bp}$ of flanking sequence and designed PCR primers using Oligo 7 (Rychlik, 2007). Primer sequences were then used in a BLAST search (Priyam et al., 2015) against the koala genome (Johnson et al., 2018) to ensure specificity and prevent amplification of non-target sequences. Primer sequences used to amplify the three microsatellites were as follows $\left(5^{\prime}\right.$ to $\left.3^{\prime}\right)$ : PhciDBB001M3 F:TTCTCTTGTCCTTCTTGTGTC, R:TTCTCCCTACAAAGATGA TCC; PhciDCBM1 F:AGTCTGGTGTCATTAGCAATAGG, R:CTGAATGAGGC AAGGGAGAG; MHCIIDAB001M1 F:ACACTACTTCCCTGAATCTGAC, R:TAC AGTGTTACTTCATGCAGAG.

All loci were initially screened for polymorphism using DNA samples from koalas previously found to be polymorphic at MHC loci (Cheng et al., 2017) (see "Initial primer screening and optimization methods" in the Supplemental Information) before genotyping the study population at these markers. Since all three markers had similar product lengths, they were not multiplexed for typing. PCRs were carried out for each locus using the Type-it Microsatellite PCR Kit (Qiagen, Hilden, Germany) with a modified total reaction size of $10 \mu \mathrm{L}$ and the following modified primer concentrations: $0.06 \mu \mathrm{M}$ tagged primer, $0.6 \mu \mathrm{M}$ untagged primer and $0.6 \mu \mathrm{M}$ 6-FAM labelled CAG tag (Schable, Fischer \& Glenn, 2002) (see Table S3 for thermocycling conditions). Capillary electrophoresis was undertaken at the Australian Genome Research Facility using MCLAB DSMO-100 Orange Size Standard. Alleles were manually called using GeneMarker (Hulce et al., 2011). Controls included a negative control using water, and a positive control using DNA from a koala that was successfully genotyped during the initial primer development.

\section{Genotyping of non-MHC-linked microsatellites}

Koalas were genotyped at a further 15 microsatellite loci, not known to be linked to MHC, using primers from previous studies (Cristescu et al., 2009; Dennison et al., 2017; Houlden, England \& Sherwin, 1996) (Table S4). The genomic location of each microsatellite was confirmed using the NCBI koala assembly browser (Kitts et al., 2015). All microsatellites were located on scaffolds not containing any MHC genes, and seven were $>10 \mathrm{~kb}$ away from any genes. Seven markers (Pcin05, Pcin08, Pcin11, Pcin20, Pcin21, Pcin22 and Pcin23) were split into three multiplexes and typed using a fluorescently labelled (6-FAM) CAG-tag (Schable, Fischer \& Glenn, 2002) (Table S4), with PCRs carried out using the Type-it Microsatellite PCR Kit (Qiagen, Hilden, Germany) (as above). The remaining eight markers were amplified separately using a fluorescently labelled (HEX or 6-FAM) M13 tail (0.6 $\mu \mathrm{M})$ (Schuelke, 2000) or forward primer (Table S4). PCRs were carried out in a $10 \mu \mathrm{L}$ reaction volume containing $1 \times$ PCR buffer, $2.5 \mathrm{mM}$

$\mathrm{MgCl}, 0.2 \mathrm{mM}$ dNTPs (Apex; Genesee Scientific, San Deigo, CA, USA), $0.2 \mu \mathrm{M}$ forward primer, $0.6 \mu \mathrm{M}$ reverse primer and 0.5 U AmpliTaq Gold (Applied Biosystems, 
Waltham, MA, USA) (see Table S3 for thermocycling conditions). Samples were genotyped on an ABI 3130xl using an internal GeneScan 500 ROX size standard and alleles were automatically called then manually checked using GeneMapper (ABI).

\section{Microsatellite diversity}

Approximately $20 \%$ of the koalas were re-genotyped to determine genotyping error rate. Tests for evidence of null alleles, deviation from Hardy-Weinberg equilibrium, and linkage disequilibrium were performed to ensure all of the non-MHC and MHC markers were suitable for use in the final statistical analysis (Methods and Results for these analyses are provided in "Marker diversity" in the Supplemental Information and Table S5).

Standardized heterozygosity $\left(\mathrm{H}_{\mathrm{s}}\right)$ was calculated as a measure of individual multilocus heterozygosity at both the non-MHC and MHC markers using the Rhh package (Alho, Välimäki \& Merilä, 2010) in $\mathrm{R}$. We chose this method, as $\mathrm{H}_{\mathrm{s}}$ gives equal weighting to all loci examined despite variation in the number and frequency of alleles present across the markers used (Aparicio, Ortego \& Cordero, 2006; Coltman et al., 1999). A Spearman's rank correlation between standardized heterozygosity at MHC-linked markers and standardized heterozygosity at non-MHC markers was also performed to test whether MHC diversity and genome-wide diversity were correlated. This was necessary to determine whether any MHC-associated mate choice findings were by-products of genome-wide variation (Ferrandiz-Rovira et al., 2016).

\section{Statistical analysis}

GLMs were used to test the three mate choice hypotheses at pre-copulatory, postcopulatory and offspring survival stages using the three binomial response variables: copulation success, breeding success and offspring success respectively (defined above). In each model, the predictor variables (male heterozygosity, pair similarity and allele presence/absence) were as described in the sections that follow. Multicollinearity of predictor variables in all models was checked by calculating VIFs, and model predictors were standardized to facilitate inference across predictors, as described above.

\section{Quantity of alleles}

To test whether mating success was influenced by genome-wide quantity of alleles, male standardized heterozygosity $\left(\mathrm{H}_{\mathrm{s}}\right)$ (non-MHC or MHC markers) was modelled as the predictor, with copulation, breeding and offspring success for each male as separate response variables. For MHC, we also tested heterozygosity each locus individually (coded 1/0 for heterozygote/homozygote). Year of first pairing for each male was included to account for changes in the program over time (year of first pairing was highly correlated with year; $\rho=0.98, p=<0.01$ ). For copulation models, male age at first pairing was also included as a predictor to account for the influence of male age on copulation success (see Results).

\section{Genetic compatibility}

To test whether genome-wide genetic compatibility influenced mating success, we modelled molecular coancestry (allele sharing, evaluated using MolKin v 2.0; 
Gutiérrez et al., 2005) as a predictor of copulation, breeding or offspring success. We used molecular coancestry, because meaningful estimates of allele frequencies are difficult to calculate for captive populations with complex pedigrees and managed mating strategies (Ivy et al., 2016). Pairwise similarity at MHC loci was calculated using Wetton's formula (Parkin et al., 1987): $\mathrm{D}_{\mathrm{AB}}=2 \mathrm{~F}_{\mathrm{AB}} /\left(\mathrm{F}_{\mathrm{A}}+\mathrm{F}_{\mathrm{B}}\right)$; where, $\mathrm{F}_{\mathrm{AB}}$ is the total number of unique MHC-linked microsatellite alleles shared by a male (A) and a female (B) across the typed loci; and $\mathrm{F}_{\mathrm{A}}$ and $\mathrm{F}_{\mathrm{B}}$ are, respectively, the total number of alleles of the male (A) and female (B) (Parkin et al., 1987). This formula is commonly used to determine similarity at MHC loci (Huchard et al., 2010; Olsson et al., 2003) and enabled us to assess each MHC locus (DA, DB and DC) separately (other similarity estimators rely on multi-locus data). The first year of pairing for each pair was added to all models as an additional predictor. For copulation models, male age at first pairing and the total number of years paired together were also included.

\section{Advantage of particular alleles}

Under the advantage of the particular alleles hypothesis, the null hypothesis that specific MHC alleles do not influence mating success was tested by coding each male with a $1 / 0$ predictor indicating the presence or absence, respectively, of each allele of the three MHC-linked loci (Sepil et al., 2012); and modelling these predictors separately against each of the response variables of copulation, breeding and offspring success. Year of first pairing was included as a predictor in every model; and male age at first pairing was also included in the copulation models. A "base" model, which excluded allelic information, was fitted for each response variable across the three loci. For each response variable, models were ranked by $\mathrm{AIC}_{\mathrm{C}}$ (Burnham \& Anderson, 2002) to determine the relative level of support for each allele as a predictor of mating success. Models that were highly ranked (i.e., $\geq 2 \mathrm{AIC}_{\mathrm{C}}$ above the next best model and above the base model) were interpreted as providing strong evidence that the presence or absence of a given allele had an effect on the corresponding response variable (Sepil et al., 2012).

\section{RESULTS}

\section{Non-genetic determinants of koala mate choice}

Male age had a significant effect on copulation success (Table 2). Expected copulation success rates increased from $\sim 20 \%$ when males were 2 -years-old, to $40 \%$ when males reached 12 years of age, and decreased to below 35\% when males were 17 years or older (fitted values are taken from the regression model in Table 2). Copulation success increased significantly with increasing familiarity between pairs (Table 2). Dyads that had previously been paired together for 5 years or more had expected copulation success rates above $50 \%$ (95\% CI [0.36-0.65]), compared to the $34 \%$ success rate of dyads that had never been paired (95\% CI [0.28-0.41]; fitted values are taken from the regression model in Table 2). No association was found between female age and mating success (Table 2). None of the factors we tested influenced breeding or offspring success and could not explain the strong declines in copulation and breeding success across time (Table 2). 
Table 2 Generalized linear models of the relationships between year, age, familiarity and three measures of mating success.

\begin{tabular}{|c|c|c|c|c|c|}
\hline Response variable & $n$ & Predictor variable & Slope \pm SE & $z$-value & $p$ \\
\hline \multirow[t]{6}{*}{ Copulation success } & 964 & Year & $-0.97 \pm 0.16$ & -6.083 & $<0.001$ \\
\hline & & Female age $^{2 *}$ & $-0.53 \pm 0.29$ & -1.866 & 0.062 \\
\hline & & Female age & $-0.30 \pm 0.18$ & -1.728 & 0.084 \\
\hline & & Male age $^{2 *}$ & $-0.67 \pm 0.29$ & -2.266 & 0.023 \\
\hline & & Male age & $0.54 \pm 0.20$ & 2.713 & 0.007 \\
\hline & & Familiarity & $0.34 \pm 0.17$ & 2.031 & 0.042 \\
\hline \multirow[t]{6}{*}{ Breeding success } & 304 & Year & $-1.07 \pm 0.29$ & -3.729 & $<0.001$ \\
\hline & & Female age ${ }^{2 *}$ & $0.10 \pm 0.41$ & 0.244 & 0.807 \\
\hline & & Female age & $-0.30 \pm 0.30$ & -1.024 & 0.306 \\
\hline & & Male age ${ }^{2 *}$ & $0.37 \pm 0.46$ & 0.802 & 0.422 \\
\hline & & Male age & $-0.30 \pm 0.31$ & -0.963 & 0.335 \\
\hline & & Familiarity & $0.05 \pm 0.29$ & 0.185 & 0.853 \\
\hline \multirow[t]{6}{*}{ Offspring success } & 134 & Year & $0.89 \pm 0.45$ & 2.007 & 0.045 \\
\hline & & Female age ${ }^{2 *}$ & $-0.70 \pm 0.62$ & -1.127 & 0.260 \\
\hline & & Female age & $-0.31 \pm 0.44$ & -0.713 & 0.476 \\
\hline & & Male age ${ }^{2 *}$ & $-0.02 \pm 0.64$ & -0.038 & 0.970 \\
\hline & & Male age & $-0.33 \pm 0.50$ & -0.653 & 0.514 \\
\hline & & Familiarity & $0.64 \pm 0.49$ & 1.299 & 0.194 \\
\hline
\end{tabular}

Notes:

Predictor variables were standardized by subtracting the mean and dividing by two standard deviations (see Methods). Predictors in bold show coefficients that are statistically different from 0 at the $0.05 \alpha$ level.

"Squared term used to create a polynomial model as the relationship between age and mating success was not predicted to be linear.

\section{Microsatellite genotyping}

All koalas were genotyped at the three MHC markers and $>75 \%$ of the study population was genotyped at 13 or more of the non-MHC loci (Table S5). Genotyping error rate was very low $(0.53 \%)$. For the MHC-linked markers, the mean number of alleles per locus $\left(\mathrm{N}_{\mathrm{a}}\right)$ was 9.67 (range $7-13 ; n=3$ loci, 70 koalas), mean observed heterozygosity $\left(\mathrm{H}_{\mathrm{o}}\right)$ was $0.771 \pm 0.1(\mathrm{SE})$, and mean expected heterozygosity $\left(\mathrm{H}_{\mathrm{e}}\right)$ was $0.755 \pm 0.083$ (Table $\mathrm{S} 5$ ) Standardized heterozygosity $\left(\mathrm{H}_{\mathrm{s}}\right)$ for the MHC markers ranged from 0.432 (more homozygous) to 1.3 (more heterozygous) (Table S5). Non-MHC marker $\mathrm{H}_{\mathrm{s}}$ ranged from 0.347 (more homozygous) to 1.62 (more heterozygous). For the non-MHC markers, $\mathrm{N}_{\mathrm{a}}=6.53$ (range 2-10; $n=15$ loci, 70 koalas), $\mathrm{H}_{\mathrm{o}}=0.673 \pm 0.05$ and $\mathrm{H}_{\mathrm{e}}=0.662 \pm 0.046$ (Table S5). Standardized heterozygosity at MHC-linked loci was not correlated with standardized heterozygosity at non-MHC loci $(n=70$ koalas, $\rho=-0.06$, 95\% CI [-0.30-0.19], $p=0.614)$.

\section{Genetic determinants of koala mate choice Quantity of alleles}

For MHC-linked loci, there was a negative relationship between male $\mathrm{H}_{\mathrm{s}}$ and copulation success (Table 3A). Examining each MHC locus separately suggested that the overall trend may result primarily from heterozygosity at the MHCII DAB locus (Table 3B). Amongst those males that successfully copulated, males with higher overall $\mathrm{MHC}_{\mathrm{s}}$ 
Table 3 Generalized linear models of the relationship between male heterozygosity and mating success.

\begin{tabular}{|c|c|c|c|c|c|}
\hline Response variable & $n$ & Predictor variable* & Slope \pm SE & $z$-value & $p$ \\
\hline \multicolumn{6}{|c|}{ A. Overall MHC heterozygosity } \\
\hline \multirow[t]{4}{*}{ Copulation success } & 21 & Intercept & $-0.79 \pm 0.102$ & -7.74 & $<0.001$ \\
\hline & & Year & $-1.32 \pm 0.230$ & -5.77 & $<0.001$ \\
\hline & & Age & $0.46 \pm 0.169$ & 2.71 & 0.007 \\
\hline & & $\mathbf{H}_{\mathbf{s}}$ & $-0.51 \pm 0.217$ & -2.35 & 0.019 \\
\hline \multirow[t]{3}{*}{ Breeding success } & 17 & Intercept & $-0.77 \pm 0.201$ & -3.83 & $<0.001$ \\
\hline & & Year & $-1.51 \pm 0.414$ & -3.65 & $<0.001$ \\
\hline & & $\mathbf{H}_{\mathrm{s}}$ & $0.79 \pm 0.372$ & 2.13 & 0.034 \\
\hline \multirow[t]{3}{*}{ Offspring success } & 13 & Intercept & $1.35 \pm 0.493$ & 2.73 & 0.006 \\
\hline & & Year & $1.68 \pm 0.925$ & 1.82 & 0.069 \\
\hline & & $\mathrm{H}_{\mathrm{s}}$ & $-0.76 \pm 0.687$ & -1.10 & 0.270 \\
\hline \multicolumn{6}{|c|}{ B. Individual MHC heterozygosity } \\
\hline \multirow[t]{6}{*}{ Copulation success } & 21 & Intercept & $-0.79 \pm 0.102$ & -7.77 & $<0.001$ \\
\hline & & Year & $-1.48 \pm 0.279$ & -5.30 & $<0.001$ \\
\hline & & Age & $0.46 \pm 0.169$ & 2.75 & 0.006 \\
\hline & & DBB heterozygosity $(6,15)$ & $-0.31 \pm 0.239$ & -1.32 & 0.187 \\
\hline & & DCB heterozygosity $(3,18)$ & $-0.37 \pm 0.341$ & -1.10 & 0.273 \\
\hline & & DAB heterozygosity $(4,17)$ & $-0.73 \pm 0.346$ & -2.10 & 0.036 \\
\hline \multirow[t]{5}{*}{ Breeding success } & 17 & Intercept & $-0.79 \pm 0.211$ & -3.76 & $<0.001$ \\
\hline & & Year & $-1.40 \pm 0.489$ & -2.86 & 0.004 \\
\hline & & DBB heterozygosity $(5,12)$ & $0.55 \pm 0.379$ & 1.44 & 0.149 \\
\hline & & DCB heterozygosity $(2,15)$ & $0.82 \pm 0.563$ & 1.45 & 0.147 \\
\hline & & DAB heterozygosity $(3,14)$ & $0.97 \pm 0.846$ & 1.14 & 0.253 \\
\hline \multirow[t]{5}{*}{ Offspring success } & 13 & Intercept & $1.26 \pm 0.402$ & 3.13 & 0.002 \\
\hline & & Year & $1.83 \pm 0.881$ & 2.07 & 0.038 \\
\hline & & DBB heterozygosity $(4,12)$ & $-1.05 \pm 0.625$ & -1.69 & 0.092 \\
\hline & & DCB heterozygosity $(1,12)$ & NA & NA & NA \\
\hline & & DAB heterozygosity $(1,12)$ & NA & NA & NA \\
\hline \multicolumn{6}{|c|}{ C. Genome-wide heterozygosity } \\
\hline \multirow[t]{4}{*}{ Copulation success } & 21 & Intercept & $-0.91 \pm 0.094$ & -9.75 & $<0.001$ \\
\hline & & Year & $-1.69 \pm 0.334$ & -5.07 & $<0.001$ \\
\hline & & Age & $0.37 \pm 0.163$ & 2.28 & 0.023 \\
\hline & & $\mathrm{H}_{\mathrm{s}}$ & $-0.47 \pm 0.324$ & -1.45 & 0.146 \\
\hline \multirow[t]{3}{*}{ Breeding success } & 17 & Intercept & $-0.59 \pm 0.178$ & -3.32 & 0.001 \\
\hline & & Year & $-1.00 \pm 0.495$ & -2.03 & 0.042 \\
\hline & & $\mathrm{H}_{\mathrm{s}}$ & $0.62 \pm 0.512$ & 1.22 & 0.224 \\
\hline \multirow[t]{3}{*}{ Offspring success } & 13 & Intercept & $0.98 \pm 0.353$ & 2.79 & 0.005 \\
\hline & & Year & $1.26 \pm 0.792$ & 1.59 & 0.112 \\
\hline & & $\mathrm{H}_{\mathrm{s}}$ & $0.24 \pm 0.887$ & 0.27 & 0.788 \\
\hline
\end{tabular}

Notes:

Predictor variables were standardized by subtracting the mean and dividing by two standard deviations (see Methods).

Predictors in bold show coefficients that are statistically different from 0 at the $0.05 \alpha$ level.

"Numbers in parentheses indicate the number of homozygotes and heterozygotes respectively. Any loci with $<2$

homozygotes were not fitted but are shown in the table for completeness (denoted "NA"). 
Table 4 Generalized linear models of the relationship between pair similarity and mating success.

\begin{tabular}{|c|c|c|c|c|c|}
\hline Response variable & $n$ & Predictor variable & Slope \pm SE & $z$-value & $p$ \\
\hline \multicolumn{6}{|c|}{ A. Overall MHC Similarity } \\
\hline \multirow[t]{5}{*}{ Copulation success } & 89 & Intercept & $-1.16 \pm 0.132$ & -8.79 & $<0.001$ \\
\hline & & Year & $-0.60 \pm 0.242$ & -2.46 & 0.014 \\
\hline & & Familiarity & $0.46 \pm 0.212$ & 2.17 & 0.030 \\
\hline & & Male age & $0.44 \pm 0.241$ & 1.84 & 0.066 \\
\hline & & MHC similarity & $0.32 \pm 0.201$ & 1.59 & 0.112 \\
\hline \multirow[t]{3}{*}{ Breeding success } & 53 & Intercept & $-1.02 \pm 0.223$ & -4.59 & $<0.001$ \\
\hline & & Year & $-1.31 \pm 0.427$ & -3.08 & 0.002 \\
\hline & & MHC similarity & $0.74 \pm 0.382$ & 1.93 & 0.054 \\
\hline \multirow[t]{3}{*}{ Offspring success } & 26 & Intercept & $1.42 \pm 0.542$ & 2.62 & 0.009 \\
\hline & & Year & $1.40 \pm 0.847$ & 1.66 & 0.098 \\
\hline & & MHC similarity & $0.40 \pm 0.701$ & 0.56 & 0.572 \\
\hline \multicolumn{6}{|c|}{ B. Individual MHC similarity } \\
\hline \multirow[t]{7}{*}{ Copulation success } & 89 & Intercept & $-1.16 \pm 0.133$ & -8.72 & $<0.001$ \\
\hline & & Year & $-0.71 \pm 0.255$ & -2.77 & 0.006 \\
\hline & & Familiarity & $0.48 \pm 0.212$ & 2.28 & 0.022 \\
\hline & & Male age & $0.51 \pm 0.245$ & 2.08 & 0.038 \\
\hline & & DBB similarity & $0.44 \pm 0.227$ & 1.91 & 0.056 \\
\hline & & DCB similarity & $0.11 \pm 0.240$ & 0.45 & 0.652 \\
\hline & & DAB similarity & $-0.03 \pm 0.243$ & -0.13 & 0.900 \\
\hline \multirow[t]{5}{*}{ Breeding success } & 53 & Intercept & $-0.98 \pm 0.225$ & -4.36 & $<0.001$ \\
\hline & & Year & $-1.14 \pm 0.463$ & -2.46 & 0.014 \\
\hline & & DBB similarity & $0.61 \pm 0.434$ & 1.41 & 0.158 \\
\hline & & DCB similarity & $-0.13 \pm 0.468$ & -0.29 & 0.773 \\
\hline & & DAB similarity & $0.99 \pm 0.452$ & 2.19 & 0.029 \\
\hline \multirow[t]{5}{*}{ Offspring success } & 26 & Intercept & $1.48 \pm 0.551$ & 2.69 & 0.007 \\
\hline & & Year & $1.60 \pm 0.906$ & 1.76 & 0.078 \\
\hline & & DBB similarity & $-0.18 \pm 0.826$ & -0.22 & 0.828 \\
\hline & & DCB similarity & $0.90 \pm 0.874$ & 1.03 & 0.303 \\
\hline & & DAB similarity & $0.27 \pm 0.856$ & 0.31 & 0.753 \\
\hline \multicolumn{6}{|c|}{ C. Genome-wide similarity } \\
\hline \multirow[t]{5}{*}{ Copulation success } & 89 & Intercept & $-1.14 \pm 0.132$ & -8.65 & $<0.001$ \\
\hline & & Year & $-0.66 \pm 0.275$ & -2.42 & 0.016 \\
\hline & & Familiarity & $0.36 \pm 0.216$ & 1.67 & 0.094 \\
\hline & & Male age & $0.37 \pm 0.235$ & 1.59 & 0.111 \\
\hline & & Similarity & $0.19 \pm 0.241$ & 0.78 & 0.435 \\
\hline \multirow[t]{3}{*}{ Breeding success } & 53 & Intercept & $-1.10 \pm 0.232$ & -4.73 & $<0.001$ \\
\hline & & Year & $-1.78 \pm 0.493$ & -3.62 & $<0.001$ \\
\hline & & Similarity & $0.89 \pm 0.448$ & 1.99 & 0.046 \\
\hline \multirow[t]{3}{*}{ Offspring success } & 26 & Intercept & $1.35 \pm 0.561$ & 2.41 & 0.016 \\
\hline & & Year & $1.03 \pm 0.965$ & 1.07 & 0.284 \\
\hline & & Similarity & $0.72 \pm 0.838$ & 0.85 & 0.393 \\
\hline
\end{tabular}


Table 5 Effect of carrying specific MHCII alleles on male copulation, breeding and offspring success.

\begin{tabular}{|c|c|c|c|c|c|c|}
\hline Response variable & Locus & Allele* & $n(0,1,2)$ & Slope \pm SE & $\mathrm{AIC}_{\mathrm{C}}$ & $\mathrm{AIC}_{\mathrm{C}}$ \\
\hline \multirow[t]{22}{*}{ Copulation success } & \multirow[t]{5}{*}{$\mathrm{DBB}$} & 297 & $18 / 3 / 0$ & $-0.952 \pm 0.491$ & 96.9 & - \\
\hline & & Base & - & - & 98.7 & 1.82 \\
\hline & & 287 & $17 / 4 / 0$ & $-0.192 \pm 0.213$ & 99.9 & 3.00 \\
\hline & & 289 & $10 / 11 / 0$ & $0.047 \pm 0.196$ & 100.6 & 3.76 \\
\hline & & 277 & $5 / 11 / 5$ & $-0.004 \pm 0.194$ & 100.7 & 3.82 \\
\hline & \multirow[t]{10}{*}{$\mathrm{DCB}$} & 266 & $18 / 3 / 0$ & $-1.201 \pm 0.492$ & 94.6 & - \\
\hline & & 254 & $16 / 5 / 0$ & $-0.560 \pm 0.247$ & 95.3 & 0.73 \\
\hline & & 220 & $18 / 3 / 0$ & $0.532 \pm 0.323$ & 98.0 & 3.36 \\
\hline & & 226 & $18 / 3 / 0$ & $0.311 \pm 0.213$ & 98.6 & 3.96 \\
\hline & & Base & - & - & 98.7 & 4.07 \\
\hline & & 250 & $18 / 3 / 0$ & $0.381 \pm 0.282$ & 98.9 & 4.27 \\
\hline & & 260 & $19 / 2 / 0$ & $-0.343 \pm 0.288$ & 99.2 & 4.61 \\
\hline & & 256 & $9 / 9 / 3$ & $-0.228 \pm 0.195$ & 99.3 & 4.70 \\
\hline & & 252 & $18 / 3 / 0$ & $0.300 \pm 0.260$ & 99.4 & 4.76 \\
\hline & & 228 & $19 / 2 / 0$ & $0.364 \pm 0.361$ & 99.7 & 5.05 \\
\hline & \multirow[t]{7}{*}{$\mathrm{DAB}$} & Base & - & - & 98.7 & - \\
\hline & & 289 & $15 / 6 / 0$ & $0.335 \pm 0.237$ & 98.7 & 0.01 \\
\hline & & 297 & $14 / 4 / 3$ & $0.089 \pm 0.198$ & 100.5 & 1.80 \\
\hline & & 285 & $14 / 7 / 0$ & $-0.038 \pm 0.204$ & 100.6 & 1.97 \\
\hline & & 287 & $18 / 3 / 0$ & $-0.362 \pm 0.310$ & 99.3 & 0.62 \\
\hline & & 291 & $13 / 7 / 1$ & $-0.213 \pm 0.196$ & 99.5 & 0.80 \\
\hline & & 293 & $17 / 4 / 0$ & $-0.181 \pm 0.219$ & 100.0 & 1.31 \\
\hline \multirow[t]{18}{*}{ Breeding success } & \multirow[t]{5}{*}{ DBB } & 297 & $15 / 2 / 0$ & $1.186 \pm 0.427$ & 67.0 & - \\
\hline & & Base & - & - & 73.0 & 6.03 \\
\hline & & 289 & $7 / 10 / 0$ & $-0.199 \pm 0.325$ & 74.7 & 7.65 \\
\hline & & 287 & $15 / 2 / 0$ & $0.026 \pm 0.327$ & 75.0 & 8.02 \\
\hline & & 277 & $3 / 10 / 4$ & $-0.024 \pm 0.308$ & 75.0 & 8.02 \\
\hline & \multirow[t]{10}{*}{$\mathrm{DCB}$} & 266 & $15 / 2 / 0$ & $1.186 \pm 0.427$ & 67.0 & - \\
\hline & & 260 & $16 / 1 / 0$ & $1.180 \pm 0.511$ & 69.1 & 2.12 \\
\hline & & 254 & $13 / 4 / 0$ & $0.883 \pm 0.410$ & 70.3 & 3.26 \\
\hline & & Base & - & - & 73.0 & 6.03 \\
\hline & & 228 & $15 / 2 / 0$ & $0.099 \pm 0.507$ & 75.0 & 7.99 \\
\hline & & 220 & $14 / 3 / 0$ & $0.017 \pm 0.634$ & 75.0 & 8.03 \\
\hline & & 226 & $15 / 2 / 0$ & $-0.936 \pm 0.396$ & 69.0 & 2.02 \\
\hline & & 252 & $14 / 3 / 0$ & $-0.902 \pm 0.419$ & 70.1 & 3.11 \\
\hline & & 250 & $15 / 2 / 0$ & $-0.619 \pm 0.452$ & 73.1 & 6.07 \\
\hline & & 256 & $6 / 9 / 2$ & $-0.031 \pm 0.319$ & 75.0 & 8.02 \\
\hline & \multirow[t]{3}{*}{$\mathrm{DAB}$} & 289 & $11 / 6 / 0$ & $-0.999 \pm 0.394$ & 68.2 & - \\
\hline & & 291 & $11 / 6 / 0$ & $0.560 \pm 0.315$ & 71.9 & 3.62 \\
\hline & & 293 & $14 / 3 / 0$ & $0.511 \pm 0.344$ & 72.8 & 4.59 \\
\hline
\end{tabular}


Table 5 (continued).

\begin{tabular}{|c|c|c|c|c|c|c|}
\hline Response variable & Locus & Allele $^{*}$ & $n(0,1,2)$ & Slope \pm SE & $\mathrm{AIC}_{\mathrm{C}}$ & $\mathrm{AIC}_{\mathrm{C}}$ \\
\hline & & Base & - & - & 73.0 & 4.80 \\
\hline & & 285 & $12 / 5 / 0$ & $0.192 \pm 0.30$ & 74.6 & 6.39 \\
\hline & & 287 & $14 / 3 / 0$ & $-0.282 \pm 0.481$ & 74.7 & 6.46 \\
\hline & & 297 & $11 / 3 / 3$ & $0.010 \pm 0.319$ & 75.0 & 6.80 \\
\hline \multirow[t]{22}{*}{ Offspring success } & DBB & 289 & $6 / 7 / 0$ & $-0.863 \pm 0.540$ & 34.5 & - \\
\hline & & 297 & $11 / 2 / 0$ & $-0.992 \pm 0.617$ & 34.6 & 0.03 \\
\hline & & Base & - & - & 35.2 & 0.67 \\
\hline & & 277 & $3 / 7 / 0$ & $0.489 \pm 0.576$ & 36.4 & 1.92 \\
\hline & & 287 & $11 / 2 / 0$ & $0.215 \pm 0.512$ & 37.0 & 2.49 \\
\hline & $\mathrm{DCB}$ & 266 & $11 / 2 / 0$ & $-0.992 \pm 0.617$ & 34.6 & - \\
\hline & & Base & - & - & 35.2 & 0.63 \\
\hline & & 228 & $11 / 2 / 0$ & $0.825 \pm 0.718$ & 35.8 & 1.25 \\
\hline & & 250 & $11 / 2 / 0$ & $0.824 \pm 0.857$ & 36.2 & 1.60 \\
\hline & & 226 & $11 / 2 / 0$ & $0.744 \pm 0.843$ & 36.3 & 1.77 \\
\hline & & 256 & $4 / 8 / 0$ & $-0.413 \pm 0.512$ & 36.5 & 1.97 \\
\hline & & 252 & $10 / 3 / 0$ & $0.317 \pm 0.689$ & 37.0 & 2.42 \\
\hline & & 254 & $11 / 2 / 0$ & $0.208 \pm 0.563$ & 37.1 & 2.50 \\
\hline & & 220 & $11 / 2 / 0$ & $0.085 \pm 1.361$ & 37.2 & 2.63 \\
\hline & & 260 & $12 / 1 / 0$ & $-0.011 \pm 0.582$ & 37.2 & 2.63 \\
\hline & $\mathrm{DAB}$ & Base & - & - & 35.2 & - \\
\hline & & 285 & $8 / 5 / 0$ & $-0.618 \pm 0.488$ & 35.6 & 0.36 \\
\hline & & 293 & $10 / 3 / 0$ & $0.295 \pm 0.531$ & 36.9 & 1.69 \\
\hline & & 287 & $11 / 2 / 0$ & $0.330 \pm 0.691$ & 37.0 & 1.77 \\
\hline & & 297 & $9 / 3 / 0$ & $0.226 \pm 0.510$ & 37.0 & 1.80 \\
\hline & & 289 & $8 / 5 / 0$ & $-0.084 \pm 0.587$ & 37.2 & 1.98 \\
\hline & & 291 & $8 / 5 / 0$ & $-0.056 \pm 0.476$ & 37.2 & 1.99 \\
\hline
\end{tabular}

Notes:

Only alleles that were present in more than one male were included.

Models shown in bold show strong evidence that the respective allele influences the corresponding response variable due to the $\mathrm{AIC}_{\mathrm{C}}$ values ranking highly $\left(\geq 2 \mathrm{AIC}_{\mathrm{C}}\right)$ above the next best model and above the base* model.

$n$ represents the number of males carrying 0,1 or 2 copies of the specified allele.

* All models are generalized linear models with response variables fitted as binomial trials (see Methods). All allele models include base parameters such as age and year (see Methods) plus a 1/0 binary predictor for presence/absence of the specified allele. Base models only include base parameters.

showed significantly greater breeding success rates than less heterozygous males (Table 3A). For example, our models predict that males that were heterozygous at all three MHC-linked loci had expected copulation success rates of 22\% (95\% CI [0.15-0.31]) and breeding success rates of $49 \%$ (95\% CI [0.29-0.68]), whereas males that were homozygous at all three MHC-linked loci had expected copulation success rates of $56 \%$ (95\% CI [0.34-0.77]) and breeding success rates of 9\% (95\% CI [0.02-0.32]; fitted values are taken from the regression models in Table 3). No association was found between offspring survival and male $\mathrm{H}_{\mathrm{s}}$ at $\mathrm{MHC}$ loci (Table 3). For non-MHC-linked loci, male $\mathrm{H}_{\mathrm{s}}$ did not show a significant effect on copulation, breeding or offspring success (Table 3C). Year and age had a significant influence on mating success (Table 3). 


\section{Genetic compatibility}

Similarity at MHC-linked loci did not have a significant effect on copulation success (Table 4); however, pairs with a higher similarity at the MHCII DAB-linked locus had a significantly greater breeding success rate than more dissimilar pairs (Table 4B). For example, our models predicted that pairs that share one or more alleles at the MHCII DAB locus would have an expected breeding success rate of $40 \%$ or higher (95\% CI [0.24-0.56]), compared to pairs that shared no alleles, which would have an expected breeding success rate of $20 \%$ (95\% CI [0.13-0.30]; fitted values are taken from the regression model in Table 4).

There were no significant effects of pairwise MHC similarity on offspring success (Table 4). Genome-wide (non-MHC) similarity did not have a significant effect on copulation nor offspring success; however, pairs with a higher similarity at non-MHC loci had significantly

greater breeding success rates than more dissimilar pairs (Table 4C). For example, expected breeding success rates increased from $15 \%$ (95\% CI [0.08-0.27]) to 57\% (95\% CI [0.24-0.84]) as genome-wide similarity estimates increased from 0.2 (low allele sharing at non-MHC loci between pairs) to 0.6 (high allele sharing at non-MHC loci between pairs) respectively (fitted values are taken from the regression model in Table 4). Year, familiarity and male age were all found to have the same effects on mating success as above (Table 4).

\section{Advantage of particular alleles}

Copulation success rates were higher in males that did not carry the DCB226 or DCB254 allele than males that did carry either of these alleles (Table 5). Conversely, males that carried the DCB266 allele were more likely to produce offspring than males without the allele (Table 5). Males that carried the DBB297 allele showed higher breeding success rates than males with other alleles, while males that carried the DAB289 allele showed reduced breeding success rates relative to males that did not carry the allele (Table 5). No particular alleles were found to influence offspring success (Table 5).

\section{DISCUSSION}

This is the first study to examine both genome-wide and MHC-dependent mate choice preferences, in addition to non-genetic factors, at multiple stages of the mating process in captive koalas. We reconfirmed that both age and familiarity were determinants of mating success in this species (Bercovitch et al., 2006). There was evidence of genome-wide mate preferences as well as pre-copulatory and post-copulatory MHC-dependent mate choice under all three mate choice hypotheses, (A) quantity of MHC alleles; (B) genetic compatibility between mates; and (C) advantage of particular alleles (hypotheses reviewed in Kamiya et al., 2014; Setchell \& Huchard, 2010). These results suggest that koalas use a combination of genetic, and non-genetic, mechanisms to select mates and optimize both the quantity and combination of alleles in their offspring.

\section{Non-genetic determinants of koala mate choice}

Our analysis showed that koala copulation success is significantly influenced by male age and/or the age difference between males and females, in line with previous studies (Bercovitch et al., 2006). Studies in other species suggest that females may prefer to mate 
with older males, likely due to older males being of a higher genetic quality through viability selection (Manning, 1985; Trivers, 1972). In koalas, male size, bellowing and sternal scent secretions have been found to convey age-related information (Charlton et al., 2012; Salamon \& Davies, 1998; Tobey et al., 2006), and so females may use visual, auditory and chemical cues to select mates based on age (Bercovitch et al., 2006). Here, we provide additional evidence that male age influences captive koala mate choice, although the precise chemical and auditory mechanisms by which females receive and utilize this information remain unclear (Ellis et al., 2015; Tobey, Nute \& Bercovitch, 2009).

In addition to age, we also found that familiarity may promote copulation success in captive koalas. Other mammal mate choice studies show that females have a preference for more familiar males (Roberts \& Gosling, 2004) and mating with familiar males leads to increased reproductive success (Martin \& Shepherdson, 2012). This familiar male preference often arises in territorial scent-marking species, as females encounter scent marks of locally territorial males and select these males due to their ability to defend a territory (Rich \& Hurst, 1998). Although koalas are a territorial scent-marking species (Allen et al., 2010), female koalas do not show a preference for locally territorial males in the wild (Ellis, Hale \& Carrick, 2002). The familiarity trend in our study may be driven by pairing previously successful pairs together in subsequent years, although most $(60 \%)$ of the pairings in our dataset were from first-time pairings. Further research, which directly examines the role of familiarity, is needed to confirm its influence in koala mate choice.

\section{Genetic determinants of koala mate choice}

Previous research suggests that females of many species are often more attracted to heterozygous males, and heterozygosity has been linked to numerous advantages such as greater sexual ornamentation, mating success and overall reproductive success (reviewed in Kempenaers, 2007). Despite these advantages, genome-wide heterozygosity did not influence mating success in our captive koalas. Some species also display a preference for dissimilar individuals, which may reduce inbreeding and increase genetic diversity of offspring (Ferrandiz-Rovira et al., 2016; Kempenaers, 2007). In contrast, we found a positive association between genome-wide similarity and breeding success, suggesting female koalas are more likely to produce offspring with males that are more genetically similar overall. A recent review showed mating with similar individuals can allow populations to adapt more quickly to virulent diseases and parasites (Campbell et al., 2017). Assortative mate preferences may help protect koala populations from threatening infectious diseases such as chlamydia (Polkinghorne, Hanger \& Timms, 2013) and koala retrovirus (Denner \& Young, 2013), and should be examined further. Although similar numbers of neutral microsatellite markers have been used in recent studies to examine genome-wide mating preferences (Ferrandiz-Rovira et al., 2016; Huchard et al., 2013), estimates of genome-wide diversity based on 15 microsatellites may not be sufficient, and larger numbers of markers should be employed in future studies to provide more accurate measures of genome-wide diversity (Miller et al., 2014). 
In addition to genome-wide mating preferences, many species select mates based on MHC (Table 1). Consistent with these studies, we found that koala mating success showed a significant association with male heterozygosity and pair similarity at MHC loci, as well as the presence or absence of particular MHC alleles. In contrast to the quantity of alleles hypothesis, males that were less heterozygous at MHC-linked loci showed a greater rate of copulation success. This indicates that female koalas prefer to copulate with males that have fewer alleles at MHC loci, particularly at DAB loci (we note that individual locus heterozygosity and overall MHC heterozygosity are related and do not provide multiple lines of evidence). Interestingly, among those males that did copulate, breeding success was higher for more heterozygous males. This implies that females are more likely to produce offspring when breeding with males of higher heterozygosity, than when breeding with males of lower heterozygosity. The standardized slopes of the trends at each stage were of similar magnitude (Table 3), suggesting that the effect of heterozygosity is similar at both mate choice stages. Assessed together, these results reflect differences in the pre-copulatory and post-copulatory MHC-dependent choice mechanisms in koalas.

Vertebrate females are known to select sperm based on heterozygosity or diversity at MHC loci (Wedekind, 2002; Winternitz et al., 2013). Males heterozygous at MHC loci show significantly greater fertilization success relative to homozygous males (Skarstein et al., 2005). In koalas, males with low heterozygosity at MHC loci overall (particularly at DAB loci) have a higher probability of copulating; however, more heterozygous males experience a fertilization advantage, so that their copulations are more likely to result in the production of offspring. While the benefits of breeding with heterozygous males can be explained by the increased antigenic peptide repertoire and immunocompetence of heterozygotes (Kamiya et al., 2014; Landry et al., 2001), we are unaware of any other reports where less-heterozygous males have a higher copulation success rate. Future work should investigate whether this unexpected relationship may be driven by an unmeasured male trait that is correlated with MHC heterozygosity.

Contrary to many previous findings under the genetic compatibility hypothesis (Table 1), captive koala pairs that were more similar at the MHCII DAB-linked locus had greater breeding success than less similar pairs. Female koalas were more likely to produce offspring with males that shared alleles at DAB loci, which is consistent with a greater reliance on post-copulatory MHC-dependent mechanisms of mate choice.

Numerous studies have shown that females select sperm based on the genetic dissimilarity of mates (Olsson et al., 1996; Thuman \& Griffith, 2005), particularly at MHC loci (Schwensow, Eberle \& Sommer, 2008; Yeates et al., 2009). A preference for mates that are more similar at MHC loci may evolve in response to disadvantages associated with mating with individuals that are too dissimilar, including increased risk of autoimmune disorders due to suboptimal T-cell selection (Kaufman, Völk \& Wallny, 1995), reduced recognition of foreign peptides due to T-cell loss (Vidovi \& Matzinger, 1988), and disruption of co-adapted gene complexes (Hendry et al., 2000).

Studies have shown that, in some circumstances, carrying multiple copies of the same MHC allele allows for higher disease resistance (Grimholt et al., 2003; Nuismer, 
Otto \& Blanquart, 2008). However, MHC assortative mating may make populations more vulnerable to future disease outbreaks or other stochastic events (Campbell et al., 2017). We suggest that female koalas might not solely choose more-similar mates but may rather optimize the quantity and combination of MHC alleles in the offspring (see also Milinski, 2006). A similarly complex mate choice mechanism has been demonstrated in sticklebacks (Gasterosteus aculeatus), whereby females prefer to mate with males with genotypes that, when combined with their own MHC alleles, will produce offspring with an optimal number of alleles and provide the highest possible resistance against common parasites (Milinski, 2003). A study of the numbers and combinations of MHC alleles in offspring with reference to the parents' MHC is needed to confirm whether this mechanism exists in koalas.

In line with the advantage of particular alleles hypothesis, we found that the presence of certain MHC-linked microsatellite alleles was associated with increased or decreased mating success, whilst other alleles showed no association. Since the MHC-linked microsatellites are found in non-coding regions of the genome (and likely have no direct functional consequences), this finding suggests that females are selecting for and/or against males that carry the respective MHC alleles. Although some of these models appear to provide strong evidence for the influence of certain alleles on mating success, we note cautious interpretation of these findings is warranted as small sample sizes and subject: predictor ratios limit the reliability of the models (Table 5). Even so, by using a multimodel inference framework, i.e., ranking models under information theory, we provide support for the hypothesis that some MHC-linked microsatellite alleles are associated with mating success. This is probably because they are in linkage disequilibrium with important functional MHC sequence variants that potentially play a role in disease resistance and susceptibility to common infectious diseases such as Chlamydia (Lau, Canfield \& Higgins, 2012).

Mate choice influences offspring viability in a variety of species, particularly when mating preferences are MHC-dependent (Agbali et al., 2010; Von Schantz et al., 1996). In koalas there was no association between offspring survival and mate choice preferences, however, data on offspring survival was only present for koala pairings that produced offspring ( $n=13$ males, 26 pairs, 28 offspring in total). Investigation into early joey loss will ascertain if observed mating preferences produce offspring with optimal MHC, as successful matings resulting in offspring with optimal immunity will increase offspring viability whilst suboptimal MHC will, in theory, produce early offspring deaths.

By using MHC-linked microsatellites we were able to examine three families of MHC loci to look for general patterns as well as locus-specific patterns. The majority of MHC-dependent mate choice studies in the current literature often only examine a single locus due to the limitations of MHC typing techniques (Kamiya et al., 2014). Our data indicate that some loci may play a larger role in mate choice than others, and different loci may act in different ways, further indicating the importance of examining multiple MHC loci. Huchard et al. (2013) found that female grey mouse lemurs (Microcebus murinus) chose males based on a particular MHCII locus that was under 
stronger diversifying selection than other MHCII loci. Similarly, DAB loci in the koala have previously been found to be under stronger selection than other MHCII loci (Lau et al., 2013), which may explain the strong effect of DAB on koala mate choice in the current study. Multi-locus approaches are vital in gaining a holistic understanding of MHC-dependent mate choice mechanisms (Kamiya et al., 2014) and can be easily achieved using MHC-linked microsatellite markers. Although numerous studies have confirmed MHC-linked microsatellite markers as a good proxy for MHC diversity in other species (Cheng \& Belov, 2012; Cheng et al., 2009a; Crouau-Roy et al., 1996), this association needs to be confirmed in the koala.

\section{CONCLUSIONS}

In conclusion, pair incompatibility is an important contributing factor for why many captive breeding programs are failing to reach program goals (Lees \& Wilcken, 2009). We found a significant decrease in the copulation and breeding success of San Diego Zoo koalas, indicating a potential risk to future sustainability. The age of males and familiarity of pairs played a role in mate choice. We also found evidence that genome-wide similarity and MHC-diversity were associated with mating success, and mate choice mechanisms may consequently be contributing to reduced copulation rates and breeding success. The importance of examining both genetic and non-genetic determinants of mate choice in captive populations is highlighted and will help aid future pairing recommendations in captive facilities. This has important implications, not only for the management of captive koalas, but for all conservation breeding initiatives for threatened species.

\section{ACKNOWLEDGEMENTS}

We thank Rebecca Johnson from the Australian Museum, Peter Timms from the University of the Sunshine Coast, Marc Wilkins from the University of New South Wales and other members of the koala genome consortium for allowing us to use genome data prior to publication. We thank Liz Jones, Yuanyuan Cheng and Denis O'Meally from the University of Sydney for sharing MHC annotations. We thank Chris Hamlin and her team of koala keepers at San Diego Zoo Global for studbook data and collection of samples, and Jennifer Tobey of SDZG Institute of Conservation Research for the breeding records. We thank Rebecca Gooley from the University of Sydney for technical support.

\section{ADDITIONAL INFORMATION AND DECLARATIONS}

\section{Funding}

Funding for this project was provided by the ARC (DP150101485). The funders had no role in study design, data collection and analysis, decision to publish, or preparation of the manuscript.

\section{Grant Disclosures}

The following grant information was disclosed by the authors:

ARC: DP150101485. 


\section{Competing Interests}

The authors declare that they have no competing interests.

\section{Author Contributions}

- Parice A. Brandies performed the experiments, analyzed the data, prepared figures and/or tables, authored or reviewed drafts of the paper, approved the final draft.

- Catherine E. Grueber conceived and designed the experiments, analyzed the data, authored or reviewed drafts of the paper, approved the final draft.

- Jamie A. Ivy contributed reagents/materials/analysis tools, authored or reviewed drafts of the paper, approved the final draft.

- Carolyn J. Hogg conceived and designed the experiments, authored or reviewed drafts of the paper, approved the final draft.

- Katherine Belov conceived and designed the experiments, authored or reviewed drafts of the paper, approved the final draft.

\section{Animal Ethics}

The following information was supplied relating to ethical approvals (i.e., approving body and any reference numbers):

Samples were collected under San Diego Zoo Global IACUC protocols 10-008, 10-009, 11-029, 14-034.

\section{Data Availability}

The following information was supplied regarding data availability:

The raw data are provided in a Supplemental Files.

\section{Supplemental Information}

Supplemental information for this article can be found online at http://dx.doi.org/10.7717/ peerj.5438\#supplemental-information.

\section{REFERENCES}

Abts KC, Ivy JA, DeWoody JA. 2015. Immunomics of the koala (Phascolarctos cinereus). Immunogenetics 67(5-6):305-321 DOI 10.1007/s00251-015-0833-6.

Agbali M, Reichard M, Bryjová A, Bryja J, Smith C. 2010. Mate choice for nonadditive genetic benefits correlate with MHC dissimilarity in the rose bitterling (Rhodeus ocellatus). Evolution 64(6):1683-1696 DOI 10.1111/j.1558-5646.2010.00961.x.

Alho JS, Välimäki K, Merilä J. 2010. Rhh: an R extension for estimating multilocus heterozygosity and heterozygosity-heterozygosity correlation. Molecular Ecology Resources 10(4):720-722 DOI 10.1111/j.1755-0998.2010.02830.x.

Allen CD, De Villiers DL, Manning BD, Dique DS, Burridge M, Chafer ML, Nicolson VN, Jago SC, McKinnon AJ, Booth RJ, McKee JJ, Pyne MJ, Zee YP, Lundie-Jenkins G, Theilemann P, Wilson RJ, Carrick FN, Johnston SD. 2010. Seasonal reproduction in wild and captive male koala (Phascolarctos cinereus) populations in south-east Queensland. Reproduction, Fertility and Development 22(4):695-709 DOI 10.1071/RD09113.

Aparicio JM, Ortego J, Cordero PJ. 2006. What should we weigh to estimate heterozygosity, alleles or loci? Molecular Ecology 15(14):4659-4665 DOI 10.1111/j.1365-294X.2006.03111.x. 
Asa CS, Traylor-Holzer K, Lacy RC. 2011a. Can conservation-breeding programmes be improved by incorporating mate choice? International Zoo Yearbook 45(1):203-212 DOI 10.1111/j.1748-1090.2010.00123.x.

Asa CS, Traylor-Holzer K, Lacy RC. 2011b. Mate choice as a potential tool to increase population sustainability. Towards Sustainable Population Management 12:23-25.

Balakrishnan K, Adams LE. 1995. The role of the lymphocyte in an immune response. Immunological Investigations 24(1-2):233-244 DOI 10.3109/08820139509062775.

Ballou JD, Lacy RC. 1995. Identifying genetically important individuals for management of genetic variation in pedigreed populations. In: Ballou JD, Gilpin M, Foose TJ, eds. Population Management for Survival and Recovery: Analytical Methods and Strategies in Small Population Conservation. New York: Columbia University Press, pp 76-111.

Ballou JD, Lees C, Faust LJ, Long S, Lynch C, Bingaman Lackey L, Foose TJ. 2010. Demographic and genetic management of captive populations. In: Kleiman DG, Thompson KV, Baer CK, eds. Wild Mammals in Captivity: Principles and Techniques for Zoo Management. 2nd ed. London: The University of Chicago Press, pp 219-252.

Belov K, Deakin JE, Papenfuss AT, Baker ML, Melman SD, Siddle HV, Gouin N, Goode DL, Sargeant TJ, Robinson MD, Wakefield MJ, Mahony S, Cross JGR, Benos PV, Samollow PB, Speed TP, Marshall Graves JA, Miller RD. 2006. Reconstructing an ancestral mammalian immune supercomplex from a marsupial major histocompatibility complex. PLOS Biology 4(3):e46 DOI 10.1371/journal.pbio.0040046.

Belov K, Lam MKP, Colgan DJ. 2004. Marsupial MHC class II $\beta$ genes are not orthologous to the eutherian $\beta$ gene families. Journal of Heredity 95(4):338-345 DOI 10.1093/jhered/esh049.

Belov K, Miller RD, Old JM, Young LJ. 2013. Marsupial immunology bounding ahead. Australian Journal of Zoology 61(1):24-40 DOI 10.1071/ZO12111.

Belsley DA, Kuh E, Welsch RE. 1980. Regression Diagnostics: Identifying Influential Data and Sources of Collinearity. New York: Wiley.

Bercovitch FB, Tobey JR, Andrus CH, Doyle L. 2006. Mating patterns and reproductive success in captive koalas (Phascolarctos cinereus). Journal of Zoology 270(3):512-516

DOI 10.1111/j.1469-7998.2006.00169.x.

Bonneaud C, Chastel O, Federici P, Westerdahl H, Sorci G. 2006. Complex Mhc-based mate choice in a wild passerine. Proceedings of the Royal Society B: Biological Sciences 273(1590):1111-1116 DOI 10.1098/rspb.2005.3325.

Bonneaud C, Richard M, Faivre B, Westerdahl H, Sorci G. 2005. An Mhc class I allele associated to the expression of $\mathrm{T}$-dependent immune response in the house sparrow. Immunogenetics 57(10):782-789 DOI 10.1007/s00251-005-0046-5.

Bos DH, Williams RN, Gopurenko D, Bulut Z, Dewoody JA. 2009. Condition-dependent mate choice and a reproductive disadvantage for MHC-divergent male tiger salamanders. Molecular Ecology 18(15):3307-3315 DOI 10.1111/j.1365-294X.2009.04242.x.

Burnham KP, Anderson DR. 2002. Model Selection and Multimodel Inference: A Practical Information-Theoretic Approach. New York: Springer.

Campbell LJ, Head ML, Wilfert L, Griffiths AGF. 2017. An ecological role for assortative mating under infection? Conservation Genetics 18(5):983-994

DOI 10.1007/s10592-017-0951-9.

Charlton BD, Ellis WAH, Brumm J, Nilsson K, Fitch WT. 2012. Female koalas prefer bellows in which lower formants indicate larger males. Animal Behaviour 84(6):1565-1571

DOI 10.1016/j.anbehav.2012.09.034. 
Cheng Y, Belov K. 2012. Isolation and characterisation of 11 MHC-linked microsatellite loci in the Tasmanian devil (Sarcophilus harrisii). Conservation Genetics Resources 4(2):463-465 DOI 10.1007/s12686-011-9575-4.

Cheng Y, Polkinghorne A, Gillett A, Jones EA, O’Meally D, Timms P, Belov K. 2017. Characterisation of MHC class I genes in the koala. Immunogenetics 70(2):125-133 DOI 10.1007/s00251-017-1018-2.

Cheng Y, Siddle HV, Beck S, Eldridge MDB, Belov K. 2009a. High levels of genetic variation at MHC class II DBB loci in the tammar wallaby (Macropus eugenii). Immunogenetics 61(2):111-118 DOI 10.1007/s00251-008-0347-6.

Cheng Y, Wakefield M, Siddle HV, Coggill PC, Herbert CA, Beck S, Belov K, Eldridge MDB. 2009b. Isolation and characterization of $10 \mathrm{MHC}$ Class I-associated microsatellite loci in tammar wallaby (Macropus eugenii). Molecular Ecology Resources 9(1):346-349 DOI 10.1111/j.1755-0998.2008.02401.x.

Coltman DW, Pilkington JG, Smith JA, Pemberton JM. 1999. Parasite-mediated selection against inbred soay sheep in a free-living, island population. Evolution 53(4):1259-1267 DOI 10.2307/2640828.

Consuegra S, Carlos De Leaniz CG. 2008. MHC-mediated mate choice increases parasite resistance in salmon. Proceedings of the Royal Society B: Biological Sciences 275(1641):1397-1403 DOI 10.1098/rspb.2008.0066.

Cristescu R, Cahill V, Sherwin WB, Handasyde K, Carlyon K, Whisson D, Herbert CA, Carlsson BLJ, Wilton AN, Cooper DW. 2009. Inbreeding and testicular abnormalities in a bottlenecked population of koalas (Phascolarctos cinereus). Wildlife Research 36(4):299-308 DOI 10.1071/wr08010.

Crouau-Roy B, Bouzekri N, Carcassi C, Clayton J, Contu L, Cambon-Thomsen A. 1996. Strong association between microsatellites and an HLA-B, DR haplotype (B18-DR3): implication for microsatellite evolution. Immunogenetics 43(5):255-260 DOI 10.1007/s002510050061.

Cutrera AP, Fanjul MS, Zenuto RR. 2012. Females prefer good genes: MHC-associated mate choice in wild and captive tuco-tucos. Animal Behaviour 83(3):847-856

DOI 10.1016/j.anbehav.2012.01.006.

Denner J, Young PR. 2013. Koala retroviruses: characterization and impact on the life of koalas. Retrovirology 10(1):108 DOI 10.1186/1742-4690-10-108.

Dennison S, Frankham G, Neaves L, Flanagan C, FitzGibbon S, Eldridge M, Johnson R. 2017. Population genetics of the koala (Phascolarctos cinereus) in north-eastern New South Wales and south-eastern Queensland. Australian Journal of Zoology 64(6):402-412

DOI 10.1071/zo16081.

Edward DA. 2015. The description of mate choice. Behavioral Ecology 26(2):301-310 DOI 10.1093/beheco/aru142.

Eizaguirre C, Yeates SE, Lenz TL, Kalbe M, Milinski M. 2009. MHC-based mate choice combines good genes and maintenance of MHC polymorphism. Molecular Ecology 18(15):3316-3329 DOI 10.1111/j.1365-294X.2009.04243.x.

Ellis W, FitzGibbon S, Pye G, Whipple B, Barth B, Johnston S, Seddon J, Melzer A, Higgins D, Bercovitch F. 2015. The role of bioacoustic signals in koala sexual selection: insights from seasonal patterns of associations revealed with GPS-proximity units. PLOS ONE 10(7):e0130657 DOI 10.1371/journal.pone.0130657.

Ellis WA, Hale PT, Carrick F. 2002. Breeding dynamics of koalas in open woodlands. Wildlife Research 29(1):19-25 DOI 10.1071/WR01042. 
Fa JE, Funk SM, O’Connell D. 2011. Zoo Conservation Biology. Cambridge: Cambridge University Press.

Ferrandiz-Rovira M, Allainé D, Callait-Cardinal MP, Cohas A. 2016. Mate choice for neutral and MHC genetic characteristics in Alpine marmots: different targets in different contexts? Ecology and Evolution 6(13):4243-4257 DOI 10.1002/ece3.2189.

Forsberg LA, Dannewitz J, Petersson E, Grahn M. 2007. Influence of genetic dissimilarity in the reproductive success and mate choice of brown trout-females fishing for optimal MHC dissimilarity. Journal of Evolutionary Biology 20(5):1859-1869 DOI 10.1111/j.1420-9101.2007.01380.x.

Gelman A. 2008. Scaling regression inputs by dividing by two standard deviations. Statistics in Medicine 27(15):2865-2873 DOI 10.1002/sim.3107.

Grimholt U, Larsen S, Nordmo R, Midtlyng P, Kjoeglum S, Storset A, Saebo S, Stet RJM. 2003. MHC polymorphism and disease resistance in Atlantic salmon (Salmo salar); facing pathogens with single expressed major histocompatibility class I and class II loci. Immunogenetics 55(4):210-219 DOI 10.1007/s00251-003-0567-8.

Gutiérrez J, Royo L, Álvarez I, Goyache F. 2005. MolKin v2.0: a computer program for genetic analysis of populations using molecular coancestry information. Journal of Heredity 96(6):718-721 DOI 10.1093/jhered/esi118.

Hegde AN. 2003. MHC molecules in the vomeronasal organ: contributors to pheromonal discrimination? Trends in Neurosciences 26(12):646-650 DOI 10.1016/j.tins.2003.10.001.

Hendry AP, Wenburg JK, Bentzen P, Volk EC, Quinn TP. 2000. Rapid evolution of reproductive isolation in the wild: evidence from introduced salmon. Science 290(5491):516-518 DOI 10.1126/science.290.5491.516.

Houlden BA, England P, Sherwin WB. 1996. Paternity exclusion in koalas using hypervariable microsatellites. Journal of Heredity 87(2):149-152 DOI 10.1093/oxfordjournals.jhered.a022972.

Huchard E, Baniel A, Schliehe-Diecks S, Kappeler PM. 2013. MHC-disassortative mate choice and inbreeding avoidance in a solitary primate. Molecular Ecology 22(15):4071-4086 DOI 10.1111/mec.12349.

Huchard E, Knapp LA, Wang J, Raymond M, Cowlishaw G. 2010. MHC, mate choice and heterozygote advantage in a wild social primate. Molecular Ecology 19(12):2545-2561 DOI 10.1111/j.1365-294X.2010.04644.x.

Hulce D, Li X, Snyder-Leiby T, Liu CJ. 2011. GeneMarker ${ }^{\circledR}$ genotyping software: tools to increase the statistical power of DNA fragment analysis. Journal of Biomolecular Techniques: JBT 22:S35.

IUCN. 2016. The IUCN red list of threatened species. Version 2016-3. Available at http://www.iucnredlist.org/ (accessed April 2017).

Ivy JA, Putnam AS, Navarro AY, Gurr J, Ryder OA. 2016. Applying SNP-derived molecular coancestry estimates to captive breeding programs. Journal of Heredity 107(5):403-412 DOI 10.1093/jhered/esw029.

Johnson RN, O'Meally D, Chen Z, Etherington GJ, Ho SYW, Nash WJ, Grueber CE, Cheng Y, Whittington CM, Dennison S, Peel E, Haerty W, O'Neill RJ, Colgan D, Russell TL, Alquezar-Planas DE, Attenbrow V, Bragg JG, Brandies PA, Chong AY-Y, Deakin JE, Di Palma F, Duda Z, Eldridge MDB, Ewart KM, Hogg CJ, Frankham GJ, Georges A, Gillett AK, Govendir M, Greenwood AD, Hayakawa T, Helgen KM, Hobbs M, Holleley CE, Heider TN, Jones EA, King A, Madden D, Graves JAM, Morris KM, Neaves LE, Patel HR, Polkinghorne A, Renfree MB, Robin C, Salinas R, Tsangaras K, Waters PD, Waters SA, Wright B, Wilkins MR, Timms P, Belov K. 2018. Adaptation and conservation insights from the koala genome. Nature genetics 50:1102-1111 DOI 10.1038/s41588-018-0153-5. 
Kamiya T, O'Dwyer K, Westerdahl H, Senior A, Nakagawa S. 2014. A quantitative review of MHC-based mating preference: the role of diversity and dissimilarity. Molecular Ecology 23(21):5151-5163 DOI 10.1111/mec.12934.

Kaufman J, Völk H, Wallny HJ. 1995. A "minimal essential Mhc" and an "unrecognized Mhc": two extremes in selection for polymorphism. Immunological Reviews 143(1):63-88 DOI 10.1111/j.1600-065X.1995.tb00670.x.

Kempenaers B. 2007. Mate choice and genetic quality: a review of the heterozygosity theory. Advances in the Study of Behavior 37:189-278 DOI 10.1016/s0065-3454(07)37005-8.

Kitts PA, Church DM, Thibaud-Nissen F, Choi J, Hem V, Sapojnikov V, Smith RG, Tatusova T, Xiang C, Zherikov A, DiCuccio M, Murphy TD, Pruitt KD, Kimchi A. 2015. Assembly: a resource for assembled genomes at NCBI. Nucleic Acids Research 44(D1):D73-D80 DOI 10.1093/nar/gkv1226.

Landry C, Garant D, Duchesne P, Bernatchez L. 2001. 'Good genes as heterozygosity': the major histocompatibility complex and mate choice in Atlantic salmon (Salmo salar). Proceedings of the Royal Society of London Series B: Biological Sciences 268(1473):1279-1285 DOI 10.1098/rspb.2001.1659.

Lau Q, Canfield PJ, Higgins DP. 2012. Expression and in vitro upregulation of MHCII in koala lymphocytes. Veterinary Immunology and Immunopathology 147(1-2):35-43 DOI 10.1016/j.vetimm.2012.04.010.

Lau QT, Griffith JE, Higgins DP. 2014b. Identification of MHCII variants associated with chlamydial disease in the koala (Phascolarctos cinereus). PeerJ 2:e443 DOI 10.7717/peerj.443.

Lau Q, Jaratlerdsiri W, Griffith JE, Gongora J, Higgins DP. 2014a. MHC class II diversity of koala (Phascolarctos cinereus) populations across their range. Heredity 113(4):287-296 DOI 10.1038/hdy.2014.30.

Lau Q, Jobbins SE, Belov K, Higgins DP. 2013. Characterisation of four major histocompatibility complex class II genes of the koala (Phascolarctos cinereus). Immunogenetics 65(1):37-46 DOI 10.1007/s00251-012-0658-5.

Lees C, Wilcken J. 2009. Sustaining the Ark: the challenges faced by zoos in maintaining viable populations. International Zoo Yearbook 43(1):6-18 DOI 10.1111/j.1748-1090.2008.00066.x.

Lindburg DG, Fitch-Snyder H. 1994. Use of behavior to evaluate reproductive problems in captive mammals. Zoo Biology 13(5):433-445 DOI 10.1002/zoo.1430130506.

Manning J. 1985. Choosy females and correlates of male age. Journal of Theoretical Biology 116(3):349-354 DOI 10.1016/s0022-5193(85)80273-3.

Martin MS, Shepherdson DJ. 2012. Role of familiarity and preference in reproductive success in ex situ breeding programs: mate preference, familiarity, and reproductive success. Conservation Biology 26(4):649-656 DOI 10.1111/j.1523-1739.2012.01880.x.

Martin-Wintle MS, Shepherdson D, Zhang GQ, Zhang HM, Li DS, Zhou XP, Li RG, Swaisgood RR. 2015. Free mate choice enhances conservation breeding in the endangered giant panda. Nature Communications 6(1):10125 DOI 10.1038/ncomms10125.

Milinski M. 2003. The function of mate choice in sticklebacks: optimizing Mhc genetics. Journal of Fish Biology 63(s1):1-16 DOI 10.1111/j.1095-8649.2003.00215.x.

Milinski M. 2006. The major histocompatibility complex, sexual selection, and mate choice. Annual Review of Ecology, Evolution, and Systematics 37(1):159-186 DOI 10.1146/annurev.ecolsys.37.091305.110242.

Miller J, Malenfant R, David P, Davis C, Poissant J, Hogg J, Festa-Bianchet M, Coltman D. 2014. Estimating genome-wide heterozygosity: effects of demographic history and marker type. Heredity 112(3):240-247 DOI 10.1038/hdy.2013.99. 
Miller HC, Moore JA, Nelson NJ, Daugherty CH. 2009. Influence of major histocompatibility complex genotype on mating success in a free-ranging reptile population. Proceedings of the Royal Society B: Biological Sciences 276(1662):1695-1704 DOI 10.1098/rspb.2008.1840.

Neff BD, Garner SR, Heath JW, Heath DD. 2008. The MHC and non-random mating in a captive population of Chinook salmon. Hereditary 101(2):175-185 DOI 10.1038/hdy.2008.43.

Neff BD, Pitcher TE. 2005. Genetic quality and sexual selection: an integrated framework for good genes and compatible genes. Molecular Ecology 14(1):19-38 DOI 10.1111/j.1365-294x.2004.02395.x.

Nei M, Gu X, Sitnikova T. 1997. Evolution by the birth-and-death process in multigene families of the vertebrate immune system. Proceedings of the National Academy of Sciences of the United States of America 94(15):7799-7806 DOI 10.1073/pnas.94.15.7799.

Nuismer SL, Otto SP, Blanquart F. 2008. When do host-parasite interactions drive the evolution of non-random mating? Ecology Letters 11(9):937-946 DOI 10.1111/j.1461-0248.2008.01207.x.

Olsson M, Gullberg A, Shine R, Madsen T, Tegelström H. 1996. Sperm selection by females. Nature 383(6601):585 DOI 10.1038/383585a0.

Olsson M, Madsen T, Nordby J, Wapstra E, Ujvari B, Wittsell H. 2003. Major histocompatibility complex and mate choice in sand lizards. Proceedings of the Royal Society B: Biological Sciences 270(Suppl_2):S254-S256 DOI 10.1098/rsbl.2003.0079.

Parkin DT, Carter RE, Walters D, Wetton JH. 1987. Demographic study of a wild house sparrow population by DNA fingerprinting. Nature 327(6118):147-149 DOI 10.1038/327147a0.

Paterson S, Pemberton JM. 1997. No evidence for major histocompatibility complex-dependent mating patterns in a free-living ruminant population. Proceedings of the Royal Society B: Biological Sciences 264(1389):1813-1819 DOI 10.1098/rspb.1997.0250.

Paul A. 2002. Sexual selection and mate choice. International Journal of Primatology 23(4):877-904 DOI 10.1023/A:1015533100275.

Penn DJ, Potts WK. 1999. The evolution of mating preferences and major histocompatibility complex genes. American Naturalist 153(2):145-164 DOI 10.1086/303166.

Polkinghorne A, Hanger J, Timms P. 2013. Recent advances in understanding the biology, epidemiology and control of chlamydial infections in koalas. Veterinary Microbiology 165(3-4):214-223 DOI 10.1016/j.vetmic.2013.02.026.

Priyam A, Woodcroft BJ, Rai V, Munagala A, Moghul I, Ter F, Gibbins MA, Moon H, Leonard G, Rumpf W, Wurm Y. 2015. Sequenceserver: a modern graphical user interface for custom BLAST databases. bioRxiv preprint DOI 10.1101/033142.

Quader S. 2005. Mate choice and its implications for conservation and management. Current Science 89:1220-1229.

Radwan J, Tkacz A, Kloch A. 2008. MHC and preferences for male odour in the bank vole. Ethology 114(9):827-833 DOI 10.1111/j.1439-0310.2008.01528.x.

R Core Team. 2017. R: A Language and Environment for Statistical Computing. Vienna: $\mathrm{R}$ Foundation for Statistical Computing. Available at http://www.R-project.org/.

Rich TJ, Hurst JL. 1998. Scent marks as reliable signals of the competitive ability of mates. Animal Behaviour 56(3):727-735 DOI 10.1006/anbe.1998.0803.

Richardson DS, Komdeur J, Burke T, Von Schantz T. 2005. MHC-based patterns of social and extra-pair mate choice in the Seychelles warbler. Proceedings of the Royal Society B: Biological Sciences 272(1564):759-767 DOI 10.1098/rspb.2004.3028. 
Roberts SC, Gosling LM. 2004. Manipulation of olfactory signaling and mate choice for conservation breeding: a case study of harvest mice. Conservation Biology 18(2):548-556 DOI 10.1111/j.1523-1739.2004.00514.x.

Rose MR. 1991. Evolutionary Biology of Aging. New York: Oxford University Press.

Roth O, Sundin J, Berglund A, Rosenqvist G, Wegner KM. 2014. Male mate choice relies on major histocompatibility complex class I in a sex-role-reversed pipefish. Journal of Evolutionary Biology 27(5):929-938 DOI 10.1111/jeb.12365.

Rychlik W. 2007. OLIGO 7 primer analysis software. Methods in Molecular Biology 402:35-59 DOI 10.1007/978-1-59745-528-2_2.

Salamon M, Davies N. 1998. Identification and variation of volatile compounds in sternal gland secretions of male koalas (Phascolarctos cinereus). Journal of Chemical Ecology 24:1659-1676 DOI 10.1023/A:1020868528762.

Sauermann U, Nürnberg P, Bercovitch F, Berard J, Trefilov A, Widdig A, Kessler M, Schmidtke J, Krawczak M. 2001. Increased reproductive success of MHC class II heterozygous males among free-ranging rhesus macaques. Human Genetics 108(3):249-254 DOI $10.1007 /$ s004390100485.

Schable NA, Fischer RU, Glenn TC. 2002. Tetranucleotide microsatellite DNA loci from the dollar sunfish (Lepomis marginatus). Molecular Ecology Notes 2(4):509-511 DOI 10.1046/j.1471-8286.2002.00296.x.

Schielzeth H. 2010. Simple means to improve the interpretability of regression coefficients. Methods in Ecology and Evolution 1(2):103-113 DOI 10.1111/j.2041-210X.2010.00012.x.

Schuelke M. 2000. An economic method for the fluorescent labeling of PCR fragments. Nature Biotechnology 18(2):233-234 DOI 10.1038/72708.

Schwensow N, Eberle M, Sommer S. 2008. Compatibility counts: MHC-associated mate choice in a wild promiscuous primate. Proceedings of the Royal Society B: Biological Sciences 275(1634):555-564 DOI 10.1098/rspb.2007.1433.

Schwensow N, Fietz J, Dausmann K, Sommer S. 2008. MHC-associated mating strategies and the importance of overall genetic diversity in an obligate pair-living primate. Evolutionary Ecology 22(5):617-636 DOI 10.1007/s10682-007-9186-4.

Sepil I, Moghadam HK, Huchard E, Sheldon BC. 2012. Characterization and 454 pyrosequencing of major histocompatibility complex class I genes in the great tit reveal complexity in a passerine system. BMC Evolutionary Biology 12(1):68 DOI 10.1186/1471-2148-12-68.

Setchell JM, Charpentier MJE, Abbott KM, Wickings EJ, Knapp LA. 2010. Opposites attract: MHC-associated mate choice in a polygynous primate. Journal of Evolutionary Biology 23(1):136-148 DOI 10.1111/j.1420-9101.2009.01880.x.

Setchell JM, Huchard E. 2010. The hidden benefits of sex: evidence for MHC-associated mate choice in primate societies. BioEssays 32(11):940-948 DOI 10.1002/bies.201000066.

Skarstein F, Folstad I, Liljedal S, Grahn M. 2005. MHC and Fertilization Success in the Arctic Charr (Salvelinus alpinus). Behavioral Ecology and Sociobiology 57(4):374-380 DOI 10.1007/s00265-004-0860-Z.

Smit A, Hubley R, Green P. 2013-2015. RepeatMasker Open-4.0. Available at http://www.repeatmasker.org/cgi-bin/WEBRepeatMasker.

Sommer S. 2005. Major histocompatibility complex and mate choice in a monogamous rodent. Behavioral Ecology and Sociobiology 58(2):181-189 DOI 10.1007/s00265-005-0909-7. 
Thuman KA, Griffith SC. 2005. Genetic similarity and the nonrandom distribution of paternity in a genetically highly polyandrous shorebird. Animal Behaviour 69(4):765-770

DOI 10.1016/j.anbehav.2004.10.003.

Tobey JR, Andrus CH, Doyle L, Thompson VD, Bercovitch FB. 2006. Maternal effort and joey growth in koalas (Phascolarctos cinereus). Journal of Zoology 268(4):423-431

DOI 10.1111/j.1469-7998.2005.00041.x.

Tobey J, Nute T, Bercovitch F. 2009. Age and seasonal changes in the semiochemicals of the sternal gland secretions of male koalas (Phascolarctos cinereus). Australian Journal of Zoology 57(2):111-118 DOI 10.1071/zo08090.

Tregenza T, Wedell N. 2000. Genetic compatibility, mate choice and patterns of parentage: invited review. Molecular Ecology 9(8):1013-1027 DOI 10.1046/j.1365-294x.2000.00964.x.

Trivers R. 1972. Parental Investment and Sexual Selection. Cambridge: Biological Laboratories, Harvard University.

Vidovi D, Matzinger P. 1988. Unresponsiveness to a foreign antigen can be caused by self-tolerance. Nature 336(6196):222-225 DOI 10.1038/336222a0.

Von Schantz T, Wittzell H, Goransson G, Grahn M, Persson K. 1996. MHC genotype and male ornamentation: genetic evidence for the Hamilton-Zuk model. Proceedings of the Royal Society B: Biological Sciences 263(1368):265-271 DOI 10.1098/rspb.1996.0041.

Wedekind C. 2002. Sexual selection and life-history decisions: implications for supportive breeding and the management of captive populations. Conservation Biology 16(5):1204-1211 DOI 10.1046/j.1523-1739.2002.01217.x.

William AHE, Bercovitch FB. 2011. Body size and sexual selection in the koala. Behavioral Ecology and Sociobiology 65(6):1229-1235 DOI 10.1007/s00265-010-1136-4.

Winternitz JC, Minchey SG, Garamszegi LZ, Huang S, Stephens PR, Altizer S. 2013. Sexual selection explains more functional variation in the mammalian major histocompatibility complex than parasitism. Proceedings of the Royal Society B: Biological Sciences 280(1769):20131605 DOI 10.1098/rspb.2013.1605.

Yeates SE, Einum S, Fleming IA, Megens H-J, Stet RJM, Hindar K, Holt WV, Katrien JWVL, Gage MJG. 2009. Atlantic salmon eggs favour sperm in competition that have similar major histocompatibility alleles. Proceedings of the Royal Society B: Biological Sciences 276(1656):559-566 DOI 10.1098/rspb.2008.1257. 